\title{
An Evaluation of the Performance of the CWB NFS Model for Warm-Season Rainfall Distribution and Propagation over the East Asian Continent
}

\author{
Chung-Chieh Wang ${ }^{1, *}$, Hsiao-Ling Huang ${ }^{2}$, Jui-Lin Li ${ }^{3}$, Tzay-Ming Leou ${ }^{4}$, and George Tai-Jen Chen ${ }^{2}$ \\ ${ }^{1}$ Department of Earth Sciences, National Taiwan Normal University, Taipei, Taiwan \\ ${ }^{2}$ Department of Atmospheric Sciences, National Taiwan University, Taipei, Taiwan \\ ${ }^{3}$ Jet Propulsion Laboratory, California Institute of Technology, Pasadena, California, USA \\ ${ }^{4}$ Central Weather Bureau, Taipei, Taiwan
}

Received 24 February 2010, accepted 13 July 2010

\begin{abstract}
This study evaluates the performance of the regional operational model at Central Weather Bureau (CWB), the Nonhydrostatic Forecast System (NFS), in capturing the general distribution and eastward propagation of warm-season rainfall within the diurnal cycle in Hovmöller (longitude-time) space over the East Asian continent. The Tropical Rainfall Measuring Mission (TRMM) $0.25^{\circ}$ rain-rates are used to evaluate the NFS coarse domain (45 km) 12 - $36 \mathrm{~h}$ QPFs during May - August, 2002 - 2005 both qualitatively and quantitatively.

Our results show that the propagating rainfall signals to the lee of the Tibetan Plateau (TP) in the diurnal cycle, evident in TRMM data, are poorly captured in the NFS QPFs throughout the warm season, similar to earlier results in the United States. The nocturnal rainfall peak near the Sichuan Basin in the NFS is unclear, and the propagation is confined to a smaller region in May - June and almost missing entirely in mid-summer. Overall, the model QPFs exhibit largest disagreement with observations in June, and smallest in May.

There is a tendency for the NFS to over-predict rainfall in eastern TP. However, both the total amount and the diurnalwave amplitude are under-predicted to the lee, where a lack of propagation signals also leads to increased phase error farther downstream. A persistent phase error (at least $7 \mathrm{~h}$ ) is also found over $110-120^{\circ} \mathrm{E}$, with early morning maxima in the model but afternoon in TRMM data. Overall, the 1200 UTC model runs predict less rainfall compared to 0000 UTC runs, while the NFS also showed some improvements from 2002 to 2005 but the leeside propagation is still under-represented.
\end{abstract}

Key words: Quantitative precipitation forecast, Warm season, Non-hydrostatic forecast system, Model evaluation

Citation: Wang, C. C., H. L. Huang, J. L. Li, T. M. Leou, and G. T. J. Chen, 2011: An evaluation of the performance of the CWB NFS model for warm-season rainfall distribution and propagation over the East Asian continent. Terr. Atmos. Ocean. Sci., 22, 49-69, doi: 10.3319/TAO.2010.07.13.01(A)

\section{INTRODUCTION}

The skill of quantitative precipitation forecasts (QPFs) for the warm season at major forecast centers around the world, with Threat Scores (TS) about 0.25 - 0.30, is comparatively low to that for the cold season and even the Typhoon season (Chen et al. 1991; Olson et al. 1995). To meet the need for more accurate weather forecasts, improvement of the rainfall prediction skill in summer, when the synoptic-scale forcing tends to be weak and local forcing and thermal effects often dominate, is an urgent but challenging task (Shapiro and Thorpe 2002; Fritsch and Car-

\footnotetext{
* Corresponding author

E-mail: cwang@ntnu.edu.tw
}

bone 2004). Using radar-derived rain-rate data, Carbone et al. (2002) reported on the coherent behavior of warmseason "precipitation episodes," defined as clusters of rainproducing systems in Hovmöller (longitude-time) space, to propagate eastward to the lee of the Rockies in the United States. Moreover, these episodes are often tied to the terrain with respect to their diurnal cycle due to solar heating (e.g., Dai et al. 1999) which shows a tendency to develop over the eastern slopes of the Rockies in the afternoon then propagate across the Great Plains over night (also Ahijevych et al. 2004). This coherent behavior together with the longevity of some episodes (reaching $60 \mathrm{~h}$ in duration and $3000 \mathrm{~km}$ in traveling distance) suggest the potential to improve 
warm-season QPFs (Carbone et al. 2002). The mechanisms supporting long-lived episodes have been investigated by Trier et al. (2006). Davis et al. (2003) examined whether the propagating signals in the US exist in current operational models, including the 22-km National Centers for Environmental Prediction (NCEP) Eta model and the National Center for Atmospheric Research (NCAR) Weather Research and Forecast (WRF) model. The authors conclude that the nocturnal rainfall maxima over the Great Plains were poorly captured, consistent with the current lack of skill in warmseason QPFs (also Davis et al. 2006). Evident even in the $10-\mathrm{km}$ WRF model forecasts, this discrepancy arises from inadequate resolution and the use of cumulus parameterization scheme (CPS), leading to unresolved internal structure (specifically the cold-pool) and consequently the lack of self-propagation of mesoscale convective systems (MCSs) in these models (Davis et al. 2003).

In the East Asia, a major terrain feature, the Tibetan Plateau (TP), also exists, and nocturnal convection at its lee near the Sichuan Basin (SB) and surrounding peripheries, such as the southern slopes of the Himalayas, has been previously noted (e.g., Asai et al. 1998; Kurosaki and Kimura 2002; Barros et al. 2004). Using infrared (IR) blackbody brightness temperature $\left(T_{B B}\right)$ data, Wang et al. $(2004,2005)$ also found propagation behavior of cloud clusters with their phase tied to the TP, in a way similar to their US counterparts. The eastward shift in the peak time of summer rainfall along the Yangtze River valley near $30^{\circ} \mathrm{N}$ within the diurnal cycle, from midnight at the upper reaches (the SB area, near $105^{\circ} \mathrm{E}$ ) to morning at the middle reaches (near $110^{\circ} \mathrm{E}$ ), then afternoon at the lower reaches (near $115^{\circ} \mathrm{E}$ ), was recently confirmed by Yu et al. (2007) using rain-gauge data and by Johnson (2010) using the Tropical Rainfall Measuring Mission (TRMM) 3B42 merged satellite rain-rates.

As reviewed above, although the characteristics of rainfall distribution and the behavior of propagating episodes in relation to the diurnal cycle have been studied to some extent in East Asia, the performance of operational models has not been assessed as in the US (Davis et al. 2003). Therefore, we employed TRMM 3-h rain-rates (Huffman et al. 2007) to evaluate the performance of the Non-hydrostatic Forecast System (NFS) of the Central Weather Bureau (CWB) of Taiwan in capturing the nocturnal propagation signals of rainfall episodes to the lee of the TP. Although only the coarse domain $(45 \mathrm{~km})$ outputs from the NFS are used and the model is not expected to perform too much differently from those examined by Davis et al. (2003), an evaluation like the present one is still valuable for the following reasons. First, once known, the model's skill in warm-season QPFs over the East Asia will serve as a benchmark for future comparison for potential improvements. Second, the TRMM rain-rates also provide an update from Wang et al. $(2004,2005)$ and allow for further documentation of the propagation behavior of rainfall episodes to the lee of the
TP. Third, additional information about the performance of the NFS, perhaps unique to the East Asia, can be revealed.

\section{DATA AND METHODOLOGY}

To evaluate the performance of CWB NFS in QPFs, the dataset used in this study covered four warm seasons (May - August) from 2002 to 2005. For rainfall observations, we employ the TRMM 3B42 merged satellite rain-rates (Huffman et al. 2007). This dataset has a horizontal resolution of $0.25^{\circ} \times 0.25^{\circ}$ and is available at 3-h intervals.

The NFS model has been the operational model at CWB for regional analyses and forecasts since 2001 (Hong 2002). This model has three domains (D1, D2, and D3) with nested grids and the horizontal grid sizes are 45,15 , and 5 km, respectively (Fig. 1 and Table 1). The Arakawa-C staggering grid structure is used (Arakawa and Schubert 1974) with Lambert conformal projection and 30 terrain-following sigma $(\sigma)$ levels. While one-way feedback (large to small) is allowed, all three domains have been enlarged since 27 August 2003 (Fig. 1). Because only D1 covers the area of our primary interests, i.e., the eastern TP and its leeside, the D1 QPFs are evaluated.

The NFS performs regional objective analysis twice a day (at 0000 and 1200 UTC) using the three-dimensional (3D) multivariate optimal-interpolation (OI) analysis scheme (Lorenc 1981; Barker 1992) with the 12-h forecast from the previous run as the first guess. Subsequently, updatecycle runs are executed every $12 \mathrm{~h}$ with a forecast length of $72 \mathrm{~h}$ (Leou and Liu 2001; Seng et al. 2001). The ordinary

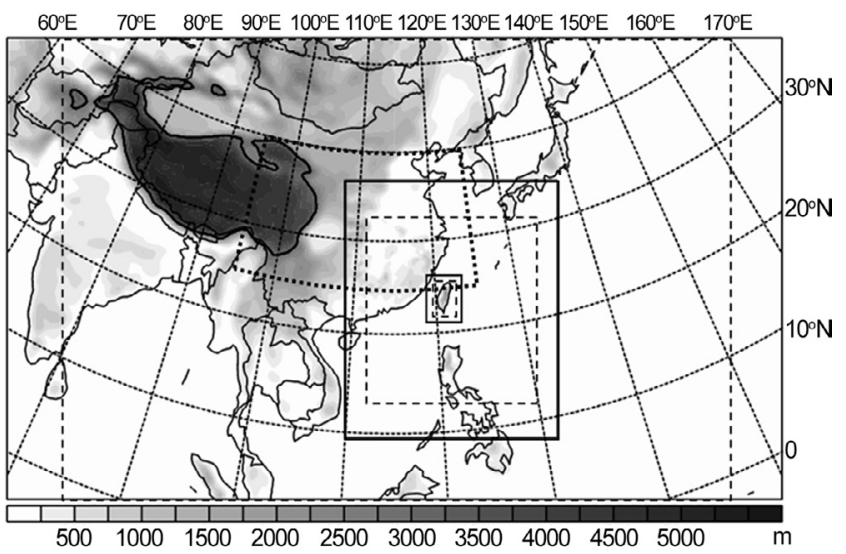

Fig. 1. The areal coverage of the CWB NFS three nested domains, D1, D2, and D3 (rectangular solid boxes). The three domains have horizontal resolution of 45,15 , and $5 \mathrm{~km}$ with dimensions of $221 \times$ $127,181 \times 193$, and $91 \times 121$ (for D1, D2, and D3), respectively. The coverage of the domains prior to 2004 is also shown in dashed boxes, with dimensions of $191 \times 127,145 \times 139$, and $61 \times 91$, respectively. The topography in D1 is shaded at intervals of $250 \mathrm{~m}$ (scale at bottom), and the thick line depicts the 3-km height contour. The dotted box shows the domain of skill score and Hovmöller calculation $\left(25-40^{\circ} \mathrm{N}\right.$, $95-125^{\circ} \mathrm{E}$ ), used for both TRMM 3-h rainfall and NFS 3-h QPF. 
update cycle (OUC) method, similar to that described by Goerss and Phoebus (1992), was used prior to December 2003. Since then, the incremental update (IU) method was implemented to perform analyses directly on $\sigma$-levels using observed deviations of variables from the local mean. The lateral boundary conditions (LBCs) of the NFS are from the forecasts of the Global Forecast System, which is the CWB operational global spectral model at a resolution of T-120 (Hong 2002; Chen et al. 2005).

The physical parameterizations of the CWB NFS include the Kuo-type CPS (Kuo 1974), the multi-layer planetary boundary layer (PBL) scheme with turbulent kinetic energy (TKE)- $\varepsilon$ closure (Detering and Etling 1985), and the radiation scheme of Harshvardhan et al. (1987). For D3, explicit simple-ice cloud microphysics of Zhao et al. (1997) is used with no cumulus parameterization. As described, the 3-h QPFs at the forecast ranges of $12-36 \mathrm{~h}$ from each run during the 2002 - 2005 warm seasons are evaluated here, since mesoscale models typically achieve higher skills around $24 \mathrm{~h}$ (e.g., Chien et al. 2002, and Fig. 2, to be discussed later). Starting from November 2007, the CWB also employs the WRF model as a semi-operational regional model. However, since the WRF model has been evaluated in the US and the NFS is developed at CWB and thus can represent the current skill of model QPFs in Taiwan, the latter is chosen for study.

To evaluate model performance, Hovmöller plots from both the TRMM rainfall and the NFS D1 QPFs at 3-h intervals are constructed. The calculation domain is selected to be $25-40^{\circ} \mathrm{N}, 95-125^{\circ} \mathrm{E}$ (Fig. 1), which covers the region where the downstream propagation of rainfall/cloud episodes in the warm season is the most evident (Wang et al. 2004, 2005). The mean diurnal cycle in Hovmöller space for different periods, such as every half month, every month, or the entire data period, is also obtained. Then, results from the observation and model forecasts are qualitatively compared to assess the capability of the CWB NFS in capturing the characteristics of eastward propagation of rainfall episodes to the lee of the TP. To perform quantitative assessment, the Equitable Threat Score (ETS) and the Bias Score (BS) at forecast ranges of $0-12,12-24,24-36$, and $36-48 \mathrm{~h}$ are computed [cf. Chien et al. (2002) and Hong (2003) for definition] for the same domain as Hovmöller calculation and for its sub-regions. In addition, harmonic analysis is also employed to examine the phase and amplitude of diurnal rainfall cycles for selected longitudinal bands.

\section{BASIC SCORES AND GENERAL RAINFALL DISTRIBUTION IN HOVMÖLLER SPACE}

Figure 2 shows the ETS and BS scores obtained by the NFS D1 (45 km) 12-h QPFs for the four forecast ranges up to $48 \mathrm{~h}$ from both 0000 and 1200 UTC runs, using TRMM data as observations. The ETS scores only reach about 0.2

Table 1. Basic configuration of the three nested NFS model domains.

\begin{tabular}{l|lll}
\hline Domain & $\mathrm{D} 1$ & $\mathrm{D} 2$ & $\mathrm{D} 3$ \\
Horizontal resolution & $45 \mathrm{~km}$ & $15 \mathrm{~km}$ & $5 \mathrm{~km}$ \\
Dimension & $221 \times 127$ & $181 \times 193$ & $91 \times 121$ \\
Southwestern corner & $5.34^{\circ} \mathrm{S}, 77.92^{\circ} \mathrm{E}$ & $9.28^{\circ} \mathrm{N}, 109.77^{\circ} \mathrm{E}$ & $20.79^{\circ} \mathrm{N}, 118.66^{\circ} \mathrm{E}$ \\
Northeastern corner & $42.93^{\circ} \mathrm{N}, 180.20^{\circ} \mathrm{E}$ & $35.27^{\circ} \mathrm{N}, 137.73^{\circ} \mathrm{E}$ & $26.34^{\circ} \mathrm{N}, 123.27^{\circ} \mathrm{E}$ \\
\hline
\end{tabular}

\section{(a) ETS}
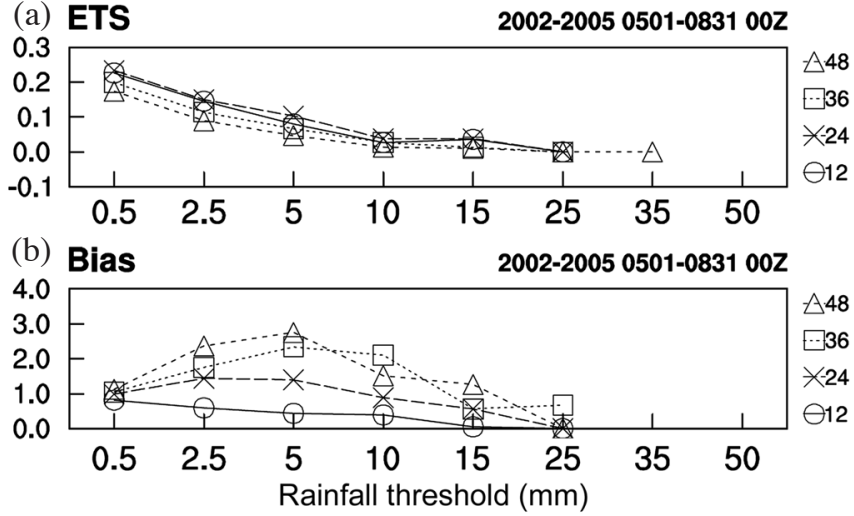

(c) ETS

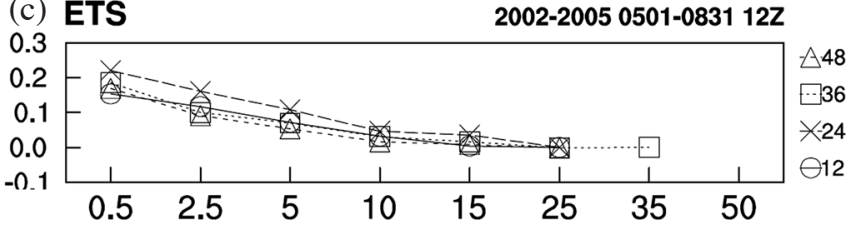

(d) Bias

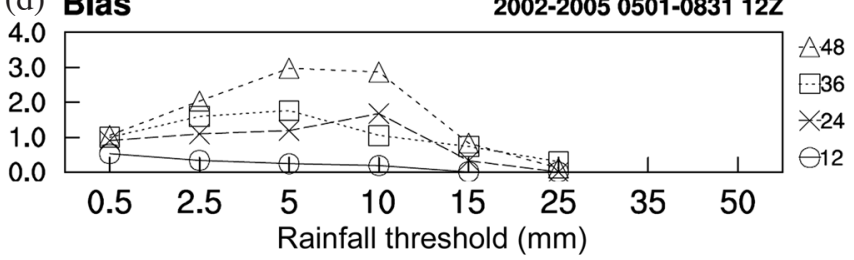

Fig. 2. (a) ETS and (b) BS of CWB NFS D1 (45 km) 12-h QPFs from the 0000 UTC runs, as a function of rainfall thresholds (mm), at forecast ranges of 0 - 12 (circle), 12 - 24 (cross), 24 - 36 (square), and $36-48 \mathrm{~h}$ (triangle) for the region of $25-40^{\circ} \mathrm{N}, 95-125^{\circ} \mathrm{E}$ (cf. Fig. 1) during May - August, 2002 - 2005. (c) (d) Same as (a) (b), but from the 1200 UTC runs. 
at the lowest threshold of $0.5 \mathrm{~mm}$, and decrease to below about 0.1 for thresholds greater than $5 \mathrm{~mm}$ (Figs. 2a, c). Thus, the ETS scores over the East Asian continent are no higher than typical values for the Mei-yu season (May June) in Taiwan, especially at higher thresholds (e.g., Chien et al. 2002; Hong 2003; Chien and Jou 2004). From the BS, there is a clear tendency for the NFS to produce more rain at longer range, especially at thresholds from 2.5 to $10 \mathrm{~mm}$ (Figs. 2b, d).

The Hovmöller diagrams of TRMM 3-h rainfall distribution between 95 and $125^{\circ} \mathrm{E}$ for May and July, 2002 and 2004 are shown in Fig. 3 as examples. It is clear that the rain was mostly associated with individual episodes that propagated eastward at speeds ranging from about 7 to $20 \mathrm{~m} \mathrm{~s}^{-1}$, with intermittent, relative dry periods in between, similar to those shown by Sato et al. (2007). The coherent propagation behavior of the episodes is more evident in May but still visible in July during the mid-summer, consistent with Wang et al. (2005). As pointed out in Wang et al. (2004), the synoptic-scale systems typically travel at a slower speed and can have modulating effects on rainfall episodes. Their roles, however, are beyond the scope of the present study.

Using the same method, Hovmöller plots of D1 $(45 \mathrm{~km}) 12$ - $36 \mathrm{~h}$ QPFs (every $3 \mathrm{~h}$ ) from the 0000 UTC runs of CWB NFS are shown in Fig. 4 for a comparison of general rainfall distribution. Here, since the $12-36 \mathrm{~h}$ forecasts from only the 0000 UTC runs are used, outputs are updated daily by those from the run next day at 1200 UTC, where a data discontinuity occurs. Direct comparisons between Figs. 3 and 4 indicate that the NFS D1 QPFs agree with the (a) TRMM 2002 05/01-05/30

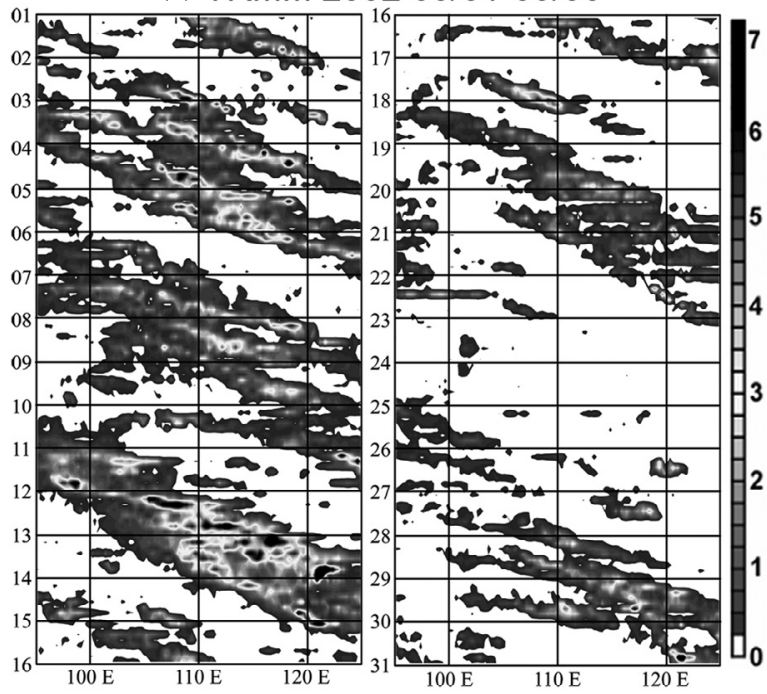

(c) TRMM 2004 05/01-05/30

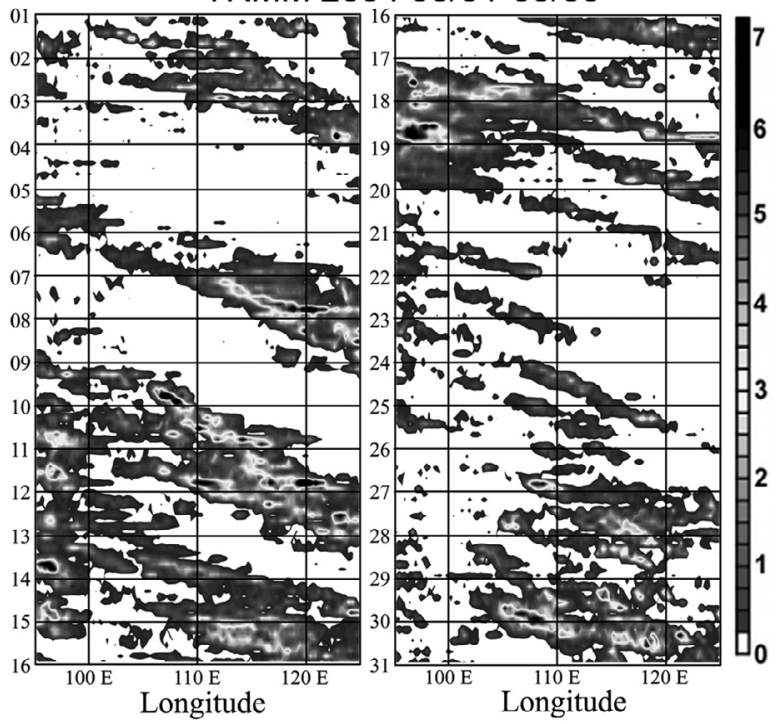

(b) TRMM 2002 06/30-07/29

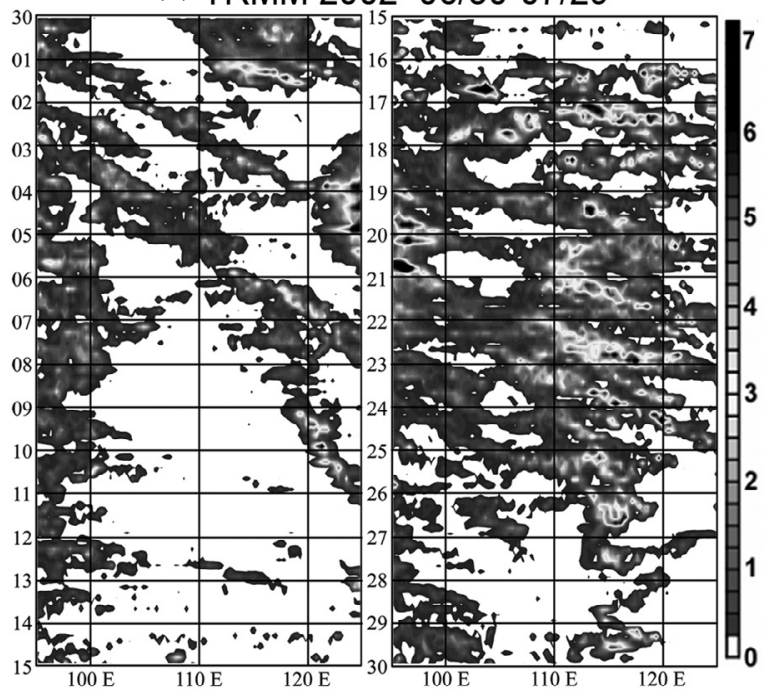

(d) TRMM 2004 06/30-07/29

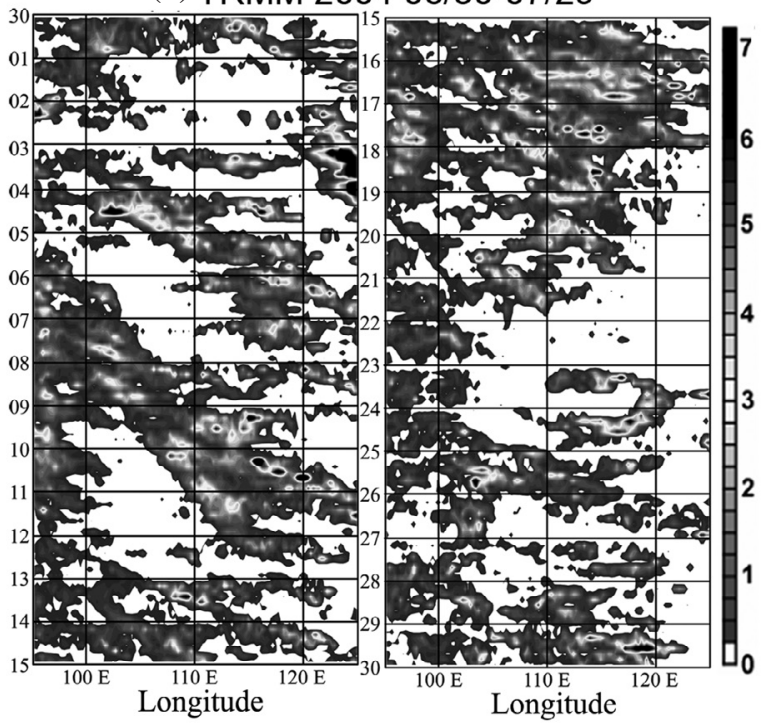

Fig. 3. Hovmöller diagrams of the $0.25^{\circ} \times 0.25^{\circ}$ TRMM 3-h rainfall (mm) over East Asia, for the month of (a) May and (b) July, 2002, and (c) May and (d) July, 2004. The calculation domain is shown in Fig. 1. 
observation in basic patterns of rainy and dry periods and in general rainfall characteristics, as the modeled rainfall is also organized into clusters having similar orientation at roughly the correct location and time (note that the time axis is shifted by $12 \mathrm{~h}$ in Fig. 4). A closer examination, however, reveals differences between TRMM data and model QPFs and potential discrepancies in the NFS. First, the eastward propagation of rainfall episodes is less evident in the model during some time periods (especially in July), for example, over 2 - 7 and 20 - 25 July 2002 (Figs. 3b and 4b), while the propagation tends to be slower in other periods, such as 17 - 20 and 27 - 30 May 2002 and 21 - 25 May 2004 (Figs. 3a, c and $4 \mathrm{a}, \mathrm{c})$. Second, the NFS model often tends to produce excessive rainfall over the eastern TP (near $95-100^{\circ} \mathrm{E}$, cf. Fig. 1), though less evident during the first half of May, while sometimes the rainfall was under-predicted over the leeside, for instance, during 19 - 22 May 2004. Third, the rain in the model occasionally appears to start over a wide area almost simultaneously, producing a leveled pattern that bears little resemblance to the observation, such as for 29 May 2004 (Figs. 3c and 4c). Here, it should be noted that the blank area for 25 - 26 May is due to missing data rather than a lack of rain. In addition, the QPFs in 2004 exhibit variation at finer scale and contain more details than those in 2002 (Fig. 4). Such differences are apparently linked to the change of the update-cycle method (from OUC to IU) in December 2003, the enlargement of domain D2 in August 2003 (cf. Fig. 1), or other improvements of the model. Overall, the NFS QPFs in Fig. 4 seem to be in reasonable agreement with the TRMM data for the general distribution (a) NFS 2002 05/01-05/31 (00 Z run)
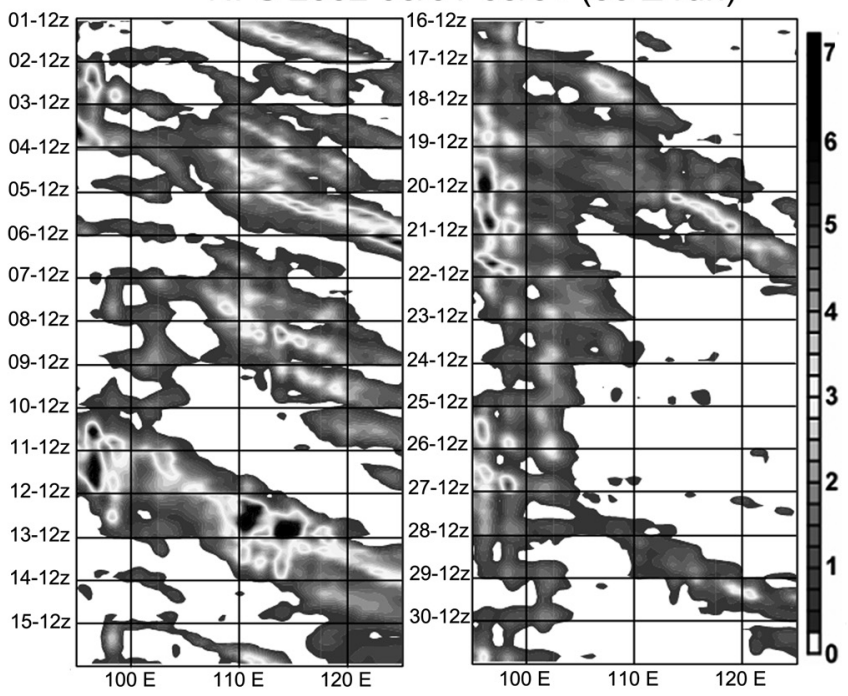

(c) NFS 2004 05/01-05/31 (00 Z run)
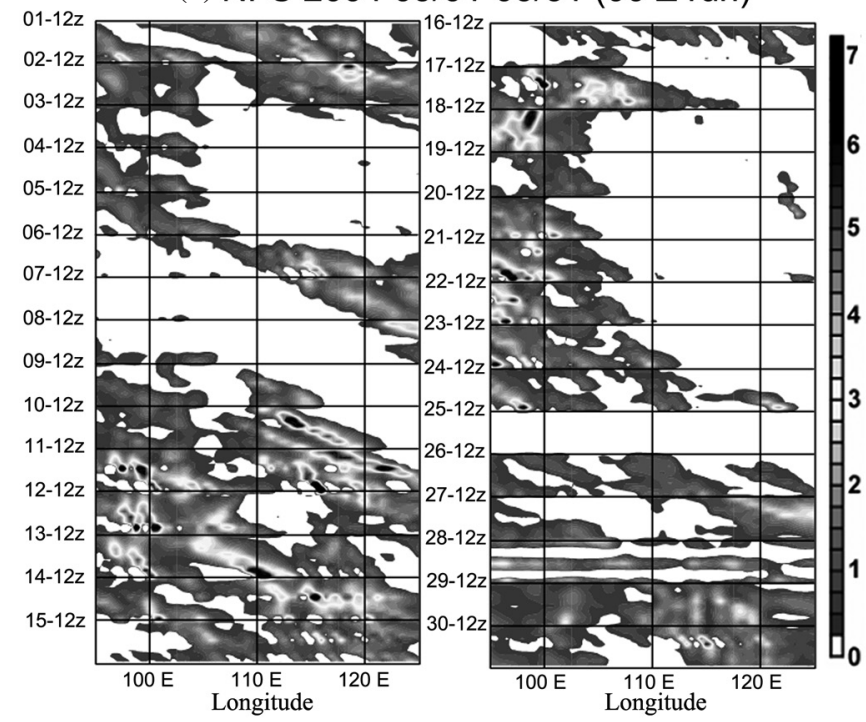

(b) NFS 2002 06/30-07/30 (00 Z run)
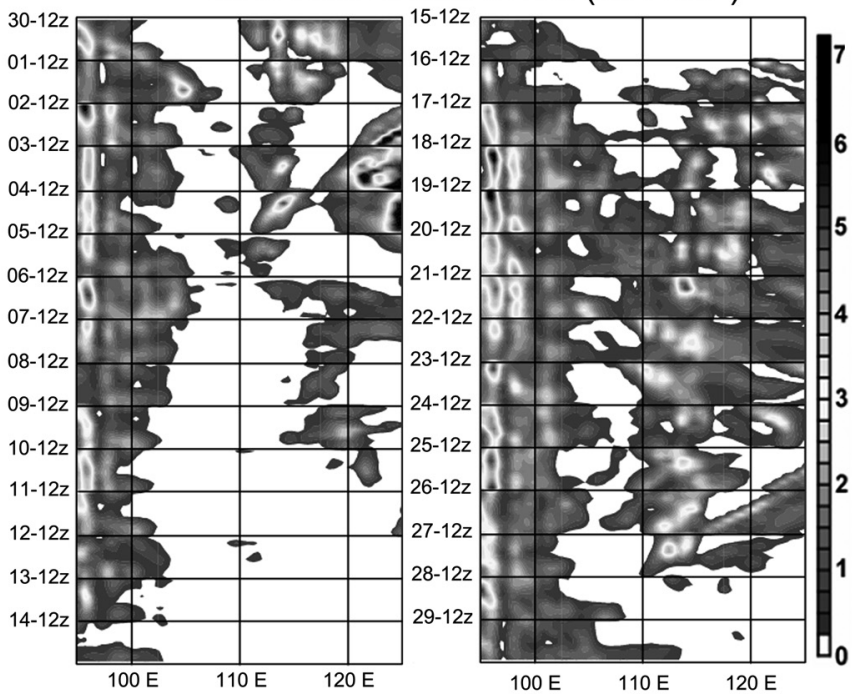

(d) NFS 2004 06/30-07/30 (00 Z run)
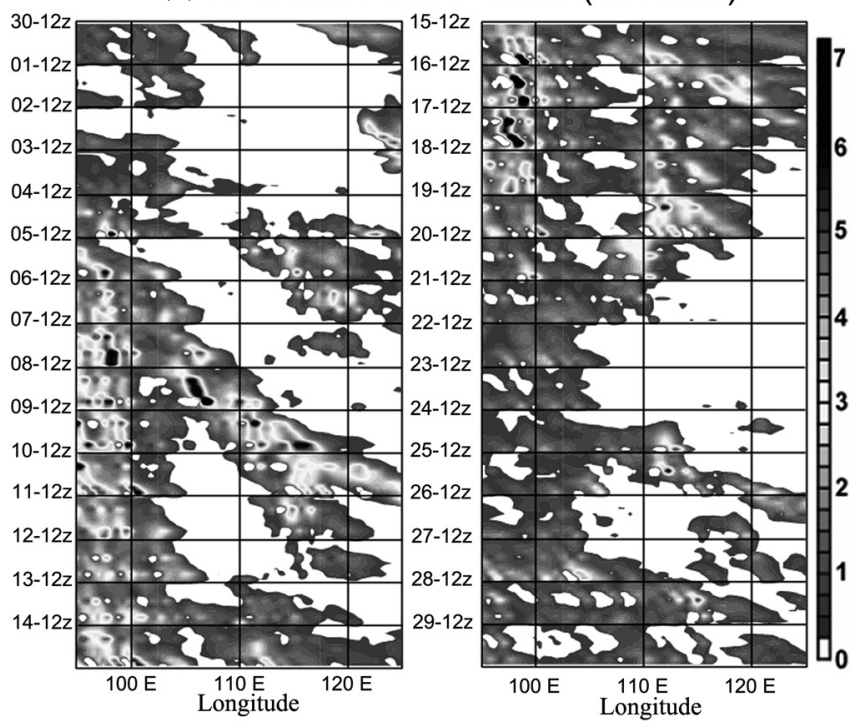

Fig. 4. Hovmöller diagrams of 3-h rainfall (mm) from the 0000 UTC runs of CWB NFS D1 (45 km) 12 - 36 h QPFs over East Asia, for the month of (a) May and (b) July, 2002, and (c) May and (d) July, 2004. The calculation domain is shown in Fig. 1. 
of rainfall and the characteristics of rainfall episodes over the East Asia. Next, we examine the averaged diurnal cycle of rainfall and its phase in relation to the terrain of TP.

\section{MEAN DIURNAL CYCLE OF RAINFALL}

The mean diurnal cycle in Hovmöller space obtained from the $0.25^{\circ}$ TRMM 3-h rainfall data for the month from May to August (2002 - 2005) is shown in Fig. 5, where the eastward propagation of rainfall signals from the eastern TP to the leeside (dashed arrows) is evident throughout the warm season. Local rainfall maxima exist around 1200 UTC (2000 LST) in late afternoon-early evening at the eastern edge of the TP (near $102^{\circ} \mathrm{E}$ ), then travel eastward across the leeside lowlands $\left(\sim 105^{\circ} \mathrm{E}\right.$, cf. Fig. 1) around or after local midnight (1600 UTC). With a zonal speed of about
$15 \mathrm{~m} \mathrm{~s}^{-1}$, the downstream propagation of rainfall signals is more pronounced in May and June and can reach about $118^{\circ} \mathrm{E}$ the next day (Figs. 5a, b). In July and August, on the other hand, the propagation is less evident and slower (at $\sim 12 \mathrm{~m} \mathrm{~s}^{-1}$ ) but can still reach about $110^{\circ} \mathrm{E}$ near $0700 \mathrm{UTC}$ (1500 LST), while the effects of daytime solar heating exhibit much control over rainfall over land farther east (110 $-120^{\circ}$ E, Figs. 5c, d), consistent with Wang et al. (2004, 2005). Note that over the ocean in $120-125^{\circ} \mathrm{E}$, daily rainfall peaks at about 2100 UTC (near dawn), especially from June to August. This is almost $180^{\circ}$ out of phase from the rainfall maxima over nearby continents (Fig. 5) and agrees with the results of Murakami (1983), Augustine (1984), and Fu et al. (1990).

The composites of the NFS 3-h QPFs in Hovmöller space for each month are shown in Fig. 6. When Figs. 5 and (a)

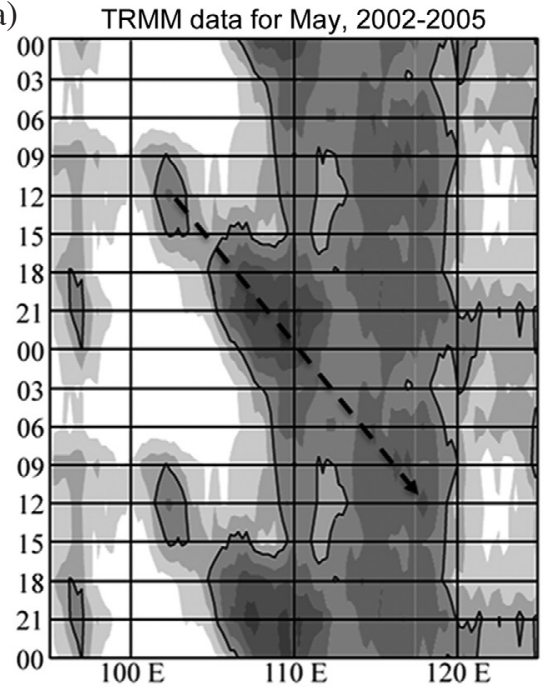

(c)

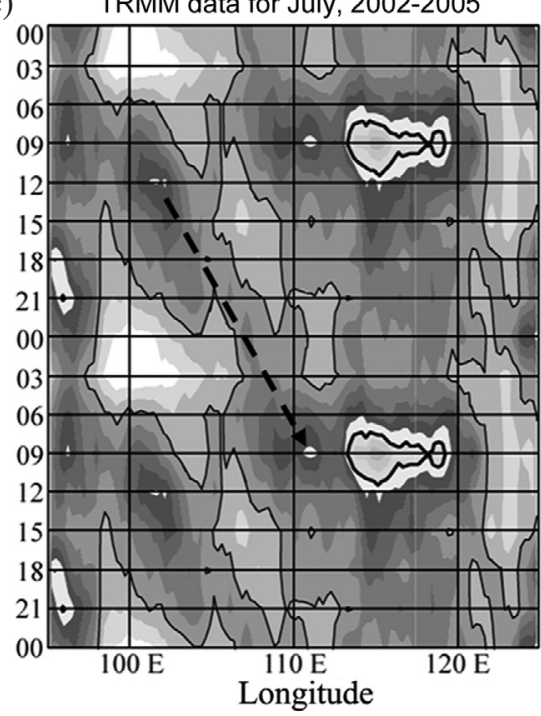

(b)

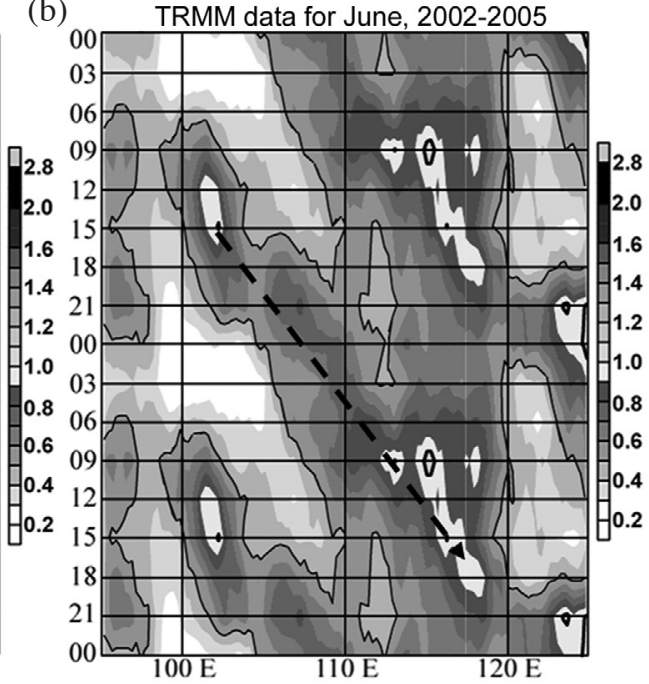

(d)

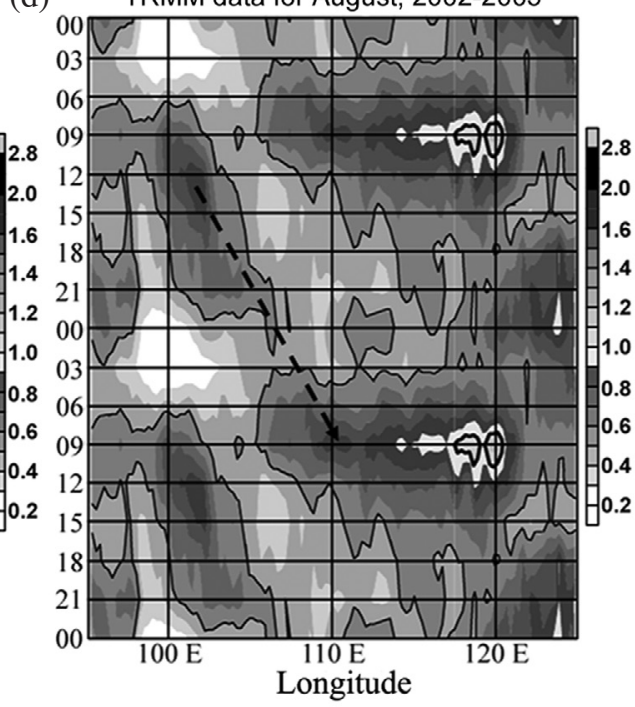

Fig. 5. Hovmöller diagrams of the mean diurnal cycle (time in UTC, repeated twice) of the $0.25^{\circ} \times 0.25^{\circ}$ TRMM 3 -h rainfall (mm) over East Asia, for (a) May, (b) June, (c) July, and (d) August, 2002 - 2005. For clarity, contours at 0.5, 1.0, and $2.0 \mathrm{~mm}$ are drawn as black, thick black, and white lines, respectively. Dashed arrow lines denote the axes of eastward propagation of rainfall signals. The calculation domain is shown in Fig. 1. 
6 are compared, it is evident that the downstream propagation of rainfall signals to the lee of the TP in NFS forecasts is much weaker than in the TRMM data. In May June when the propagation is evident, a nocturnal rainfall maximum near $105-108^{\circ} \mathrm{E}, 1800$ - 0000 UTC is observed (Figs. 5a, b). Its counterpart in the model is much less clear and seriously delayed (i.e., shifted into the daytime hours) in May, and is missing completely in June (Figs. 6a, b). As a result, the propagation in the NFS QPFs is less discernible, considerably slower $\left(<12 \mathrm{~m} \mathrm{~s}^{-1}\right)$, and confined to the west of $110^{\circ} \mathrm{E}$ in May and further limited to the west of $105^{\circ} \mathrm{E}$ in June. In July - August, when the propagation is still identifiable in Figs. 5c, d, it disappears altogether in the model (Figs. 6c, d). Results from Figs. 3 - 6 suggest that although model rainfall agrees with the observation in general patterns, it often occurs at an incorrect time within the diurnal cycle downstream from the TP. Thus, the propa- gation behavior of rainfall episodes relative to the TP in the East Asian continent is not well captured by the CWB NFS model (in its D1 QPFs) during the warm season as expected, similar to the conclusions of Davis et al. (2003) for WRF and Eta models in the US.

When compared with Fig. 5, Fig. 6 also confirms that the NFS tends to predict too much rainfall over the eastern TP, especially from May to July. Over $110-120^{\circ} \mathrm{E}$, not only there is a lack of propagation signals in the model in May - June, but much of the rain is also (zonally) stationary (Figs. 6a, b). Moreover, the maximum rainfall over 113 $120^{\circ} \mathrm{E}$ occurs near 0900 UTC (1700 LST) in TRMM data but around 0000 UTC in the model, indicating a large phase error in the NFS QPFs for much of the warm season. On the other hand, the modeled rainfall is correct in phase over the nearby ocean $\left(120-125^{\circ} \mathrm{E}\right)$, but the amount is too high in May and August (Fig. 6). Thus, near the coast of eastern
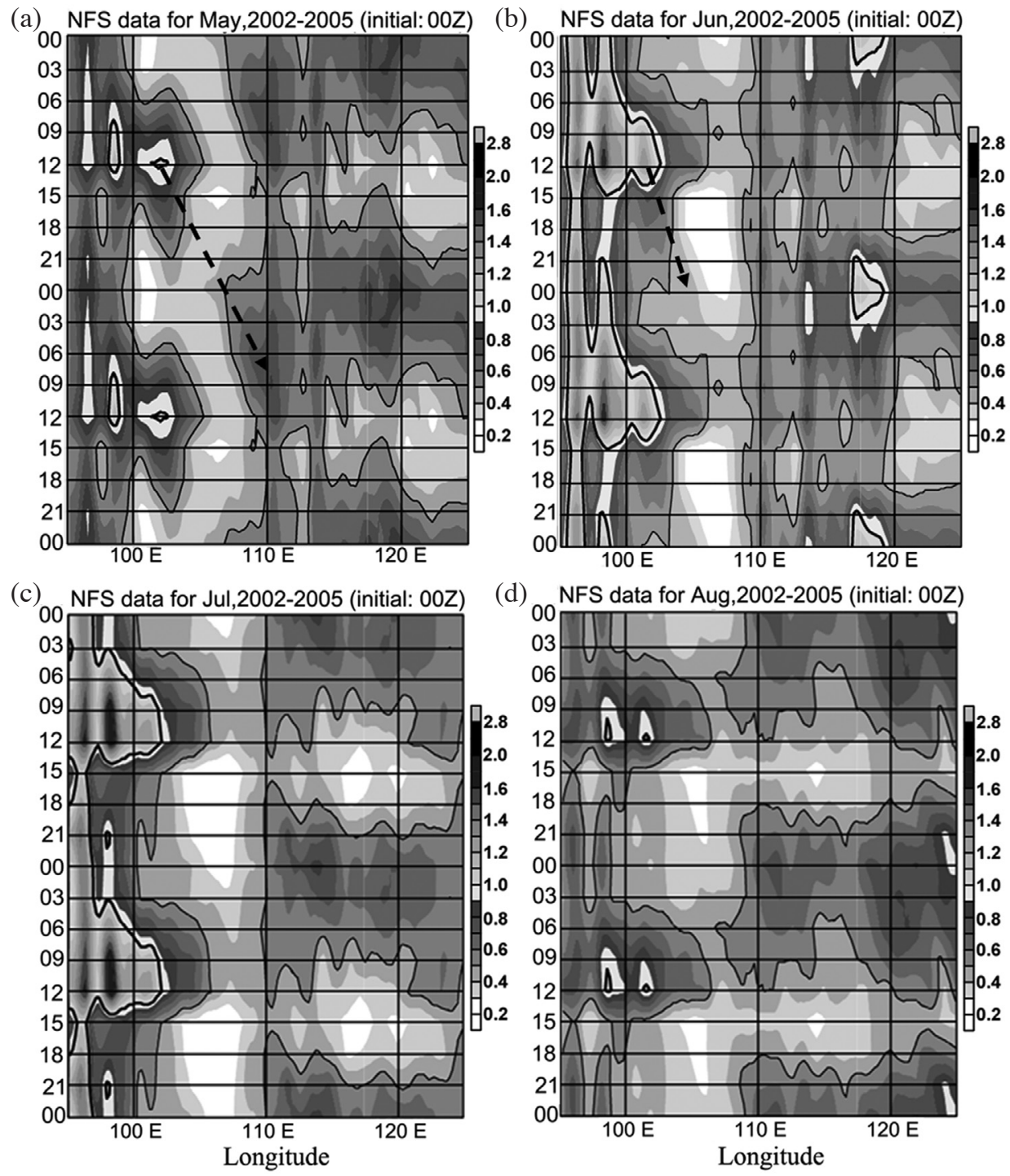

Fig. 6. Same as Fig. 5, but from the 0000 UTC runs of CWB NFS D1 (45 km) 12 - 36 h QPFs over East Asia for the warm seasons of 2002 - 2005. 
China, the summer rainfall over land and ocean is out of phase (peaking in late-afternoon over land but early-morning over ocean) in the observation, but tends to occur during late-night/early-morning hours in both regions in the NFS.

Since there are clear deficiencies in NFS QPFs over different longitudinal ranges, we compared the mean diurnal cycles for every half month to examine the persistency of the disagreements. The disagreement between observations and model QPFs is most clear in June (Fig. 7), when the signal east of $102^{\circ} \mathrm{E}$ in the model becomes weak and stationary rainfall dominates in the region of $113-120^{\circ} \mathrm{E}$ (cf. Fig. 6b). Over the eastern TP, the rainfall over-prediction (mainly during daytime hours for 0000 UTC runs) is more serious for May, the first half of June (Figs. 7a, c), and August, compared to other periods (cf. Figs. 5 and 6). The phase error over the land area of $113-120^{\circ} \mathrm{E}$ becomes evident beginning at about mid-June (Figs. 7b, d), and repre- sents one other obvious and persistent problem throughout the summer in the model. At least partially attributable to these deficiencies, the ETS scores show a drop from May to June at thresholds above $2.5 \mathrm{~mm}$, and remain relatively low in July and August (Fig. 8).

To examine whether there is some improvement in the NFS model during our data period, especially before and after the major modification in late 2003, the months of May and July in 2002 and 2004 (as in Figs. 3 and 4) were selected for comparison in Figs. 9 and 10. Although some interannual variations exist, the model performance in 2002 is quite similar to the results deduced from Fig. 6 as the propagation signals were poorly captured in both May and July (Figs. 9a, $\mathrm{b}$ and $10 \mathrm{a}, \mathrm{b})$. In 2004, on the other hand, there appears to be some improvement in model forecasts (Figs. 10c, d). The NFS QPFs show a morning maximum (around 0000 UTC) at $105^{\circ} \mathrm{E}$ in May, and some propagation signals can be seen (a)

TRMM data for 01 15 June, 2002-2005

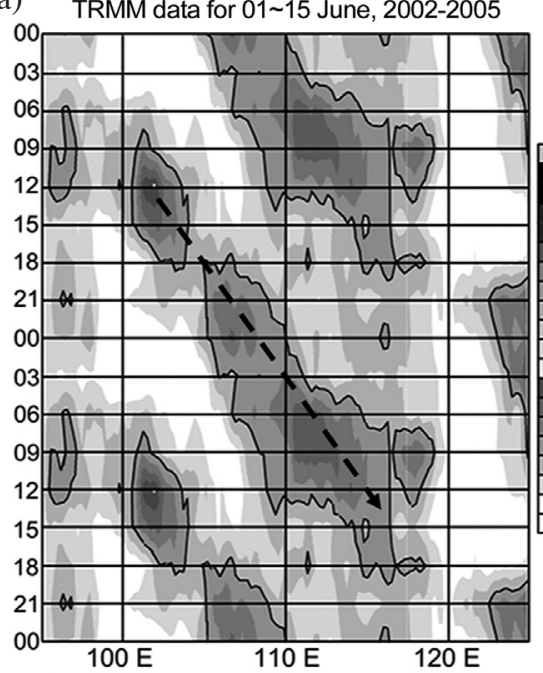

(c)

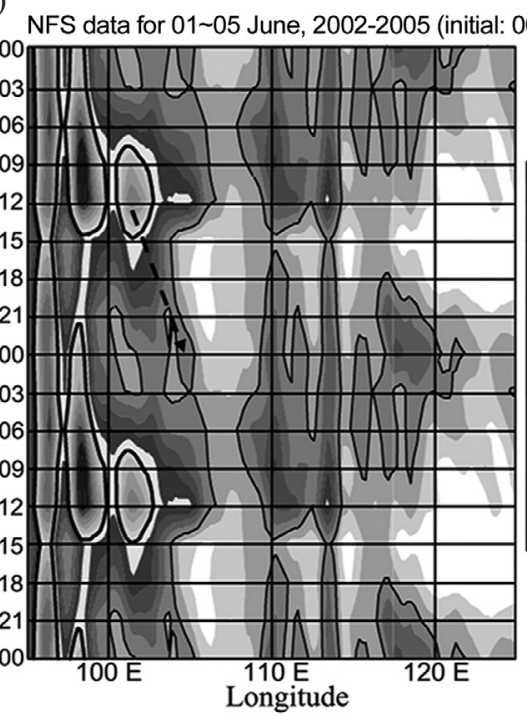

(b)

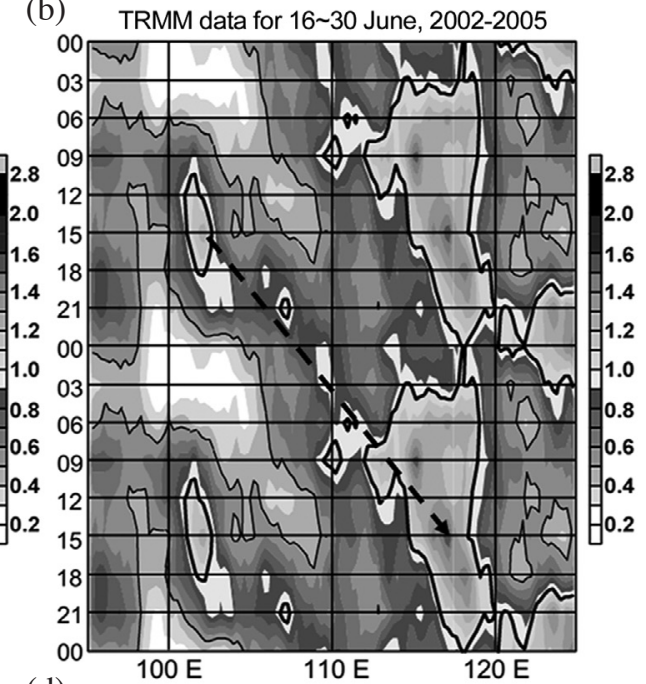

(d)

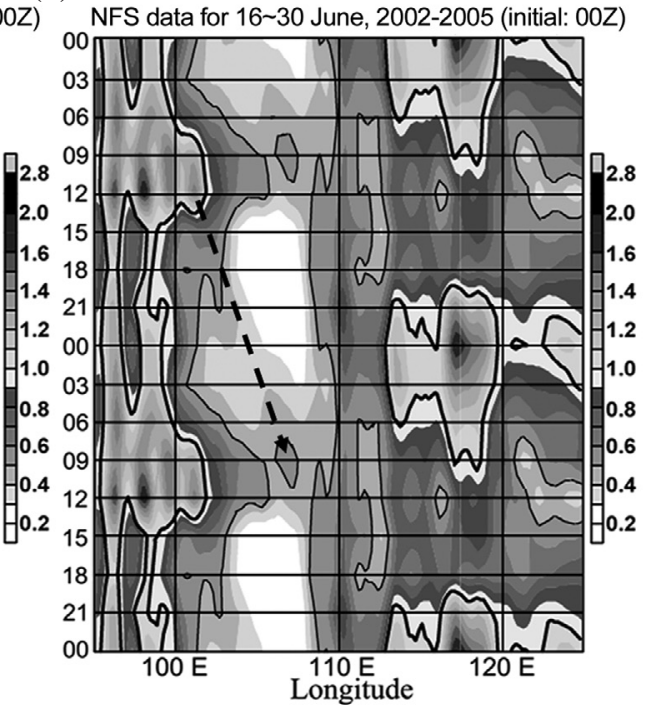

Fig. 7. (a) (b) Same as Fig. 5, except for TRMM 3-h rainfall (mm) every half month for (a) 1 - 15 and (b) 16 - 30 June, 2002 - 2005. (c) (d) Same as (a) (b), but from the 0000 UTC runs of CWB NFS D1 (45 km) 12 - 36 h QPFs over East Asia. 


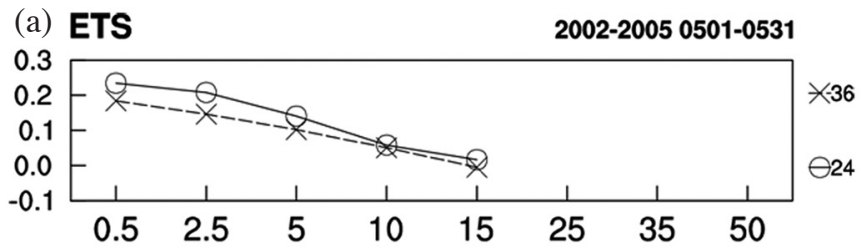

(c) ETS

2002-2005 0701-0731

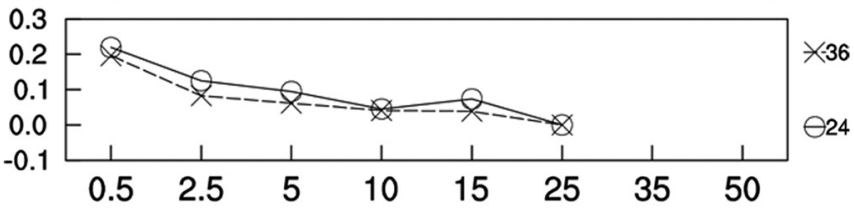

(b) ETS 2002-2005 0601-0630

(d) ETS 2002-2005 0801-0831
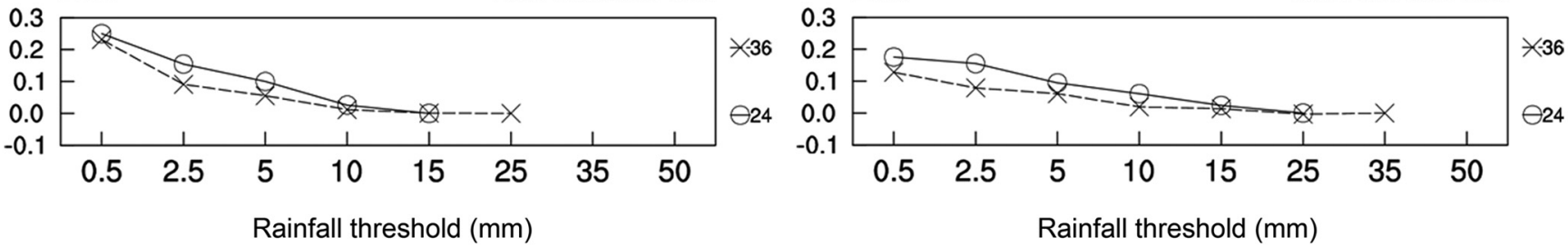

Fig. 8. ETS of CWB NFS D1 (45 km) 12-h QPFs from both the 0000 and 1200 UTC runs, as a function of rainfall thresholds (mm), at forecast ranges of 12 - 24 (circle) and 24 - 36 h (cross) in (a) May, (b) June, (c) July, and (d) August, 2002 - 2005.
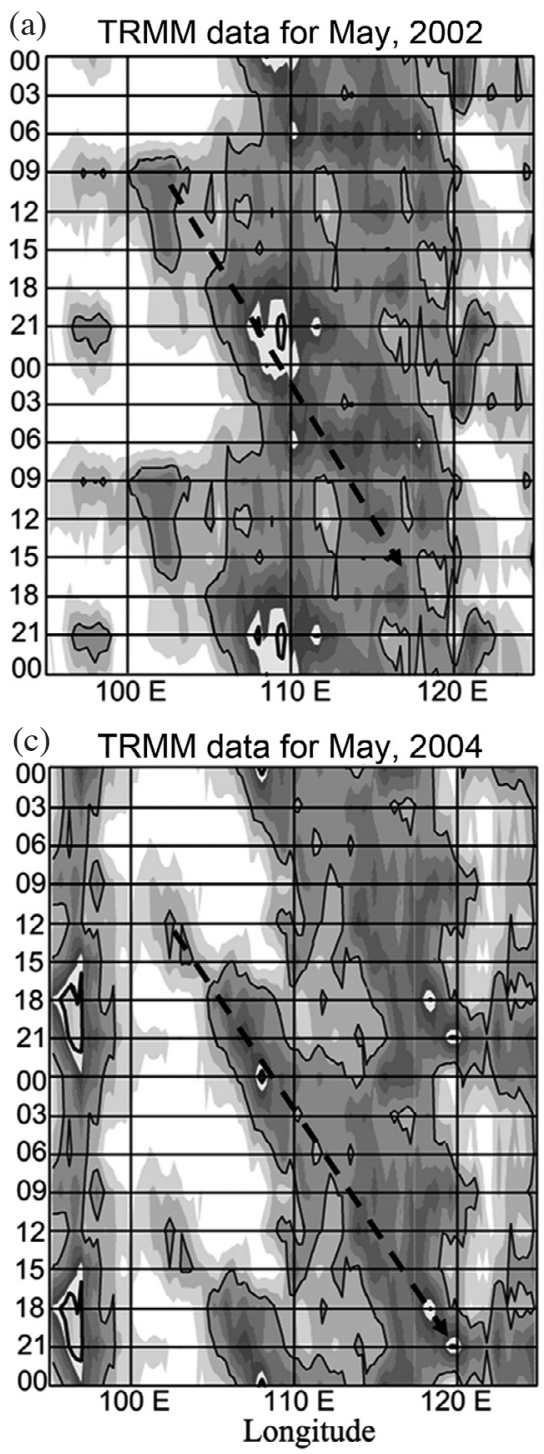

(b) TRMM data for July, 2002

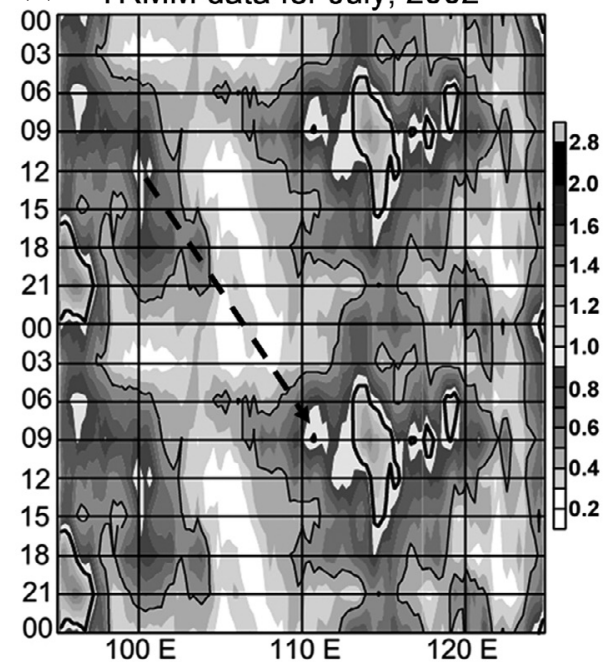

(d) TRMM data for July, 2004

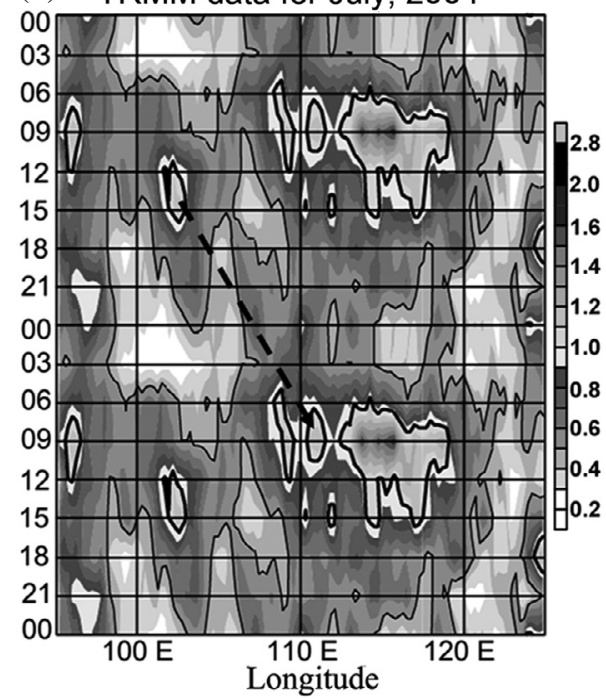

Fig. 9. Same as Fig. 5, except for (a) May and (b) July, 2002, and (c) May and (d) July, 2004. 
(a) NFS data for May, 2002 (initial: 00Z)

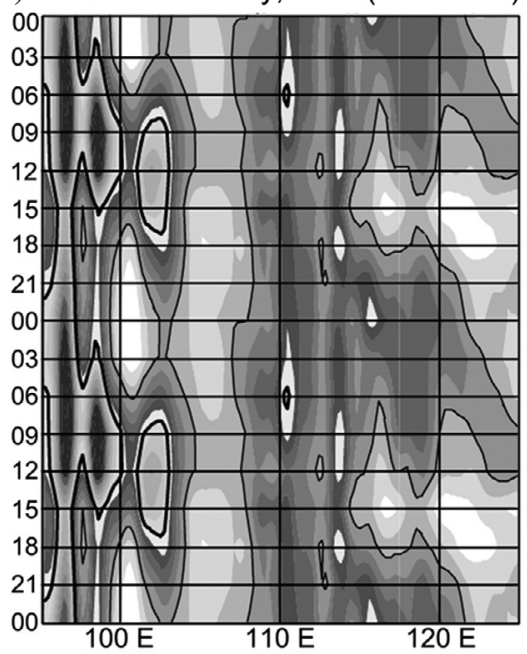

(c) NFS data for May, 2004 (initial: 00Z)

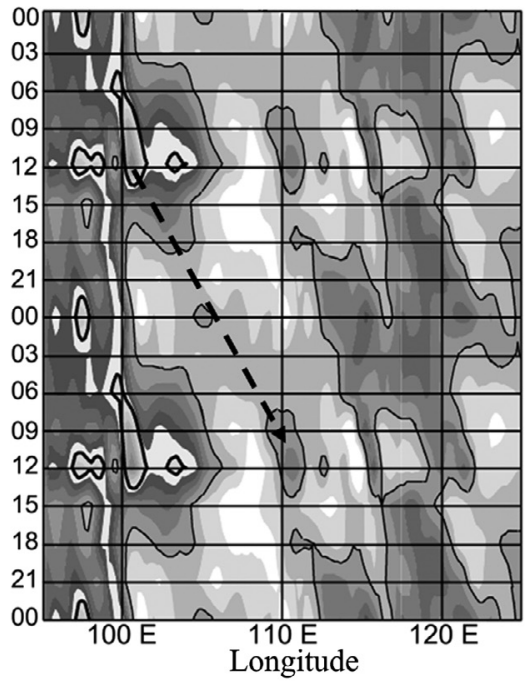

(b) NFS data for July, 2002 (initial: 00Z)

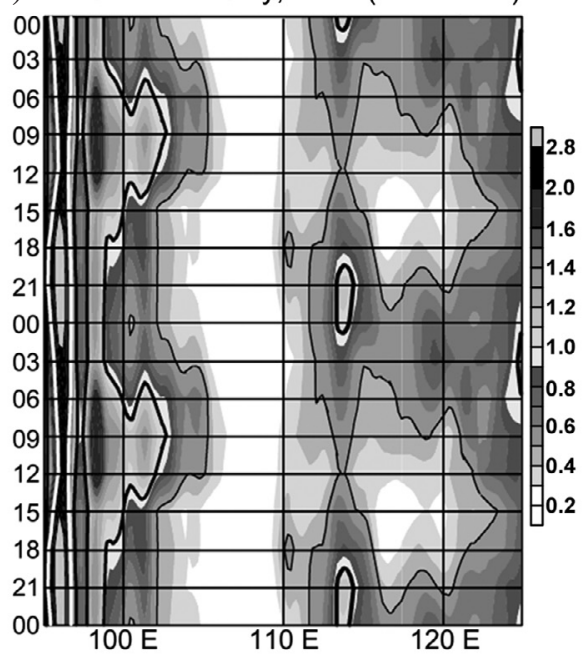

(d) NFS data for July, 2004 (initial: 00Z)

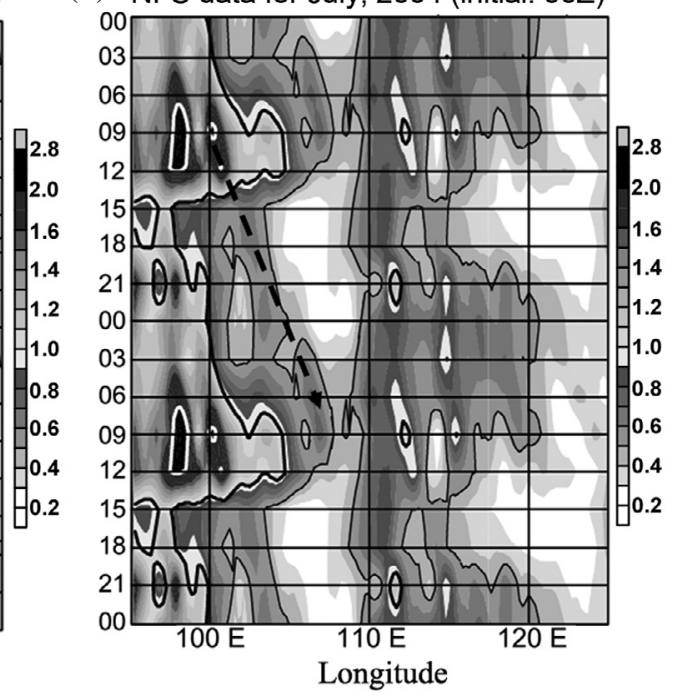

Fig. 10. Same as Fig. 9, but from the 0000 UTC runs of CWB NFS D1 (45 km) 12 - 36 h QPFs over East Asia.

from 101 to $107^{\circ} \mathrm{E}$ even in July. Thus, the rainfall propagation to the lee of the TP, though still somewhat too slow in both months, is better captured in 2004 compared to 2002 (Fig. 10). In the area of $95-100^{\circ} \mathrm{E}$, although over-prediction still exists, the excessive rainfall for May is reduced to some extent. The QPFs for 2004 also show more details than those in 2002 over $110-120^{\circ} \mathrm{E}$, in agreement with Fig. 4, but the phase of rainfall within the diurnal cycle is still erroneous in this region, particularly in July (Figs. 9 and 10). These improvements, however, are not reflected in the overall ETS scores, which have little difference among the warm seasons (not shown).

Figure 11 shows the averaged diurnal cycles of NFS 3-h QPFs from the 1200 UTC model runs in Hovmöller space from May to August, and can be compared with Fig. 6 . For each month, the two diagrams from 0000 and 1200 UTC runs in general have similar characteristics, and the down- stream propagation of rainfall signals to the lee of the TP is also ill-captured in Fig. 11. Over most regions, the 1200 UTC model runs tend to predict less rainfall throughout the summer, with exceptions near $97-100^{\circ} \mathrm{E}$ in all four months and near $125^{\circ} \mathrm{E}$ in August, both for the period of $1200-0000$ UTC (Figs. 6 and 11). On the other hand, over 0000 - 1200 UTC, there is considerably less rain near about $95-105^{\circ} \mathrm{E}$ in the 1200 UTC runs during July - August (and in June to a lesser degree). Thus, rainfall maxima west of $100^{\circ} \mathrm{E}$ appear near 1100 UTC in the 0000 UTC runs (Fig. 6), but near 2100 UTC in the 1200 UTC runs after May (Fig. 11). Despite this shift in timing, the total rainfall over the eastern TP seems less in the forecasts at 1200 UTC, implying that the over-prediction of rainfall there could be somewhat less serious. From $110-120^{\circ} \mathrm{E}$, the rainfall maxima produced by the 1200 UTC runs still occur near 0000 UTC throughout the warm season (Fig. 11), similar to the results of 0000 
(a) NFS data for May, 2002-2005 (initial: 12Z)

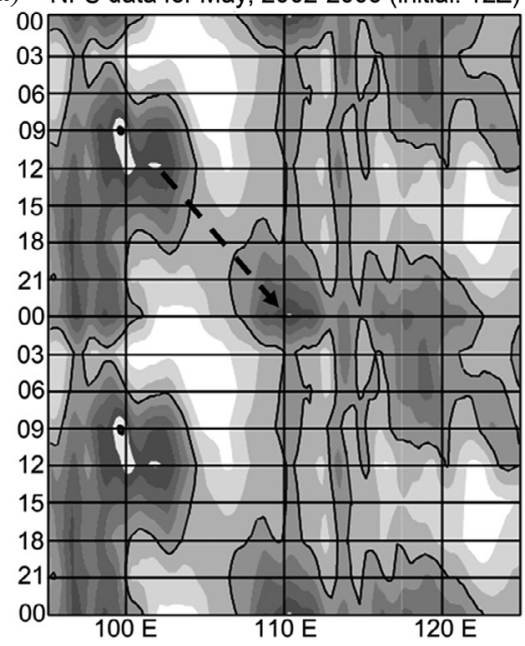

(c) NFS data for June, 2002-2005 (initial: 12Z)

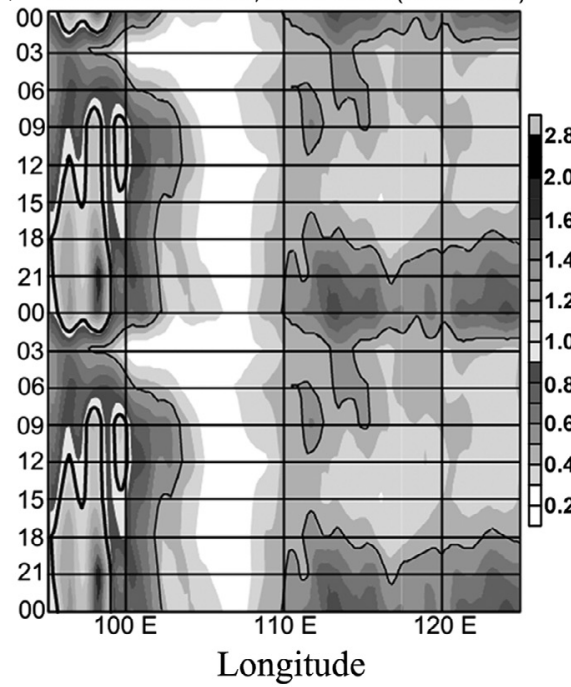

(b) NFS data for June, 2002-2005 (initial: 12Z)

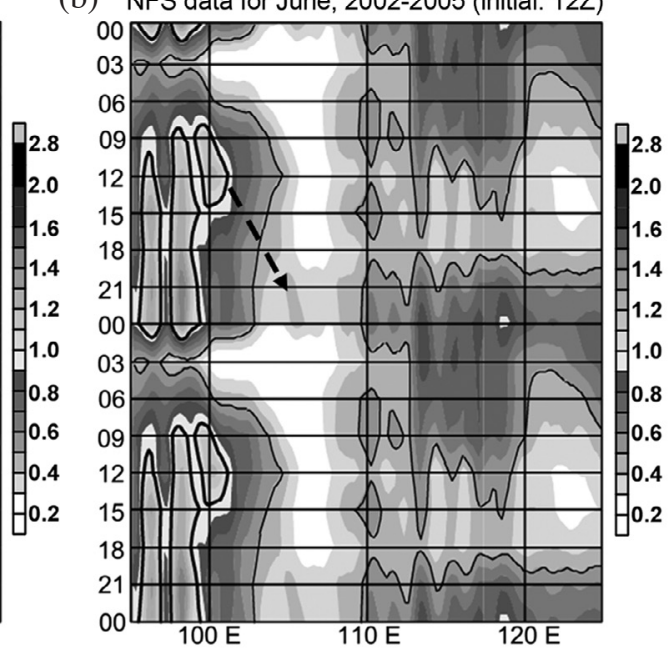

(d) NFS data for August, 2002-2005 (initial: 12Z)

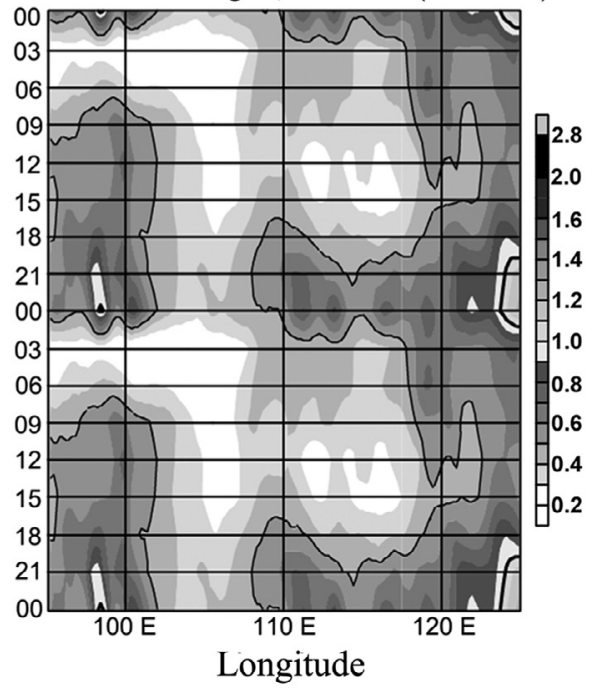

Fig. 11. Same as Fig. 6, except for the mean diurnal cycle of the 3-h rainfall (mm) from the 1200 UTC runs of CWB NFS D1 (45 km) 12 - $36 \mathrm{~h}$ QPFs.

UTC runs but different from the TRMM observation (cf. Figs. 5 and 6).

\section{HARMONIC ANALYSIS}

We selected a total of six longitudinal bands, each $3^{\circ}$ in width, for harmonic analysis of the mean diurnal rainfall cycle using Fast Fourier Transform (FFT). This allows us to quantitatively examine the phase and amplitude of diurnal (and semi-diurnal) signals both in TRMM data and NFS QPFs. The first band was $97-100^{\circ} \mathrm{E}$ over the eastern TP (cf. Fig. 1) where the NFS tends to significantly over-predict the rainfall (Figs. 5, 6, and 11). The next three bands were 101 $-104^{\circ} \mathrm{E}, 105-108^{\circ} \mathrm{E}$, and $109-112^{\circ} \mathrm{E}$, each separated by $1^{\circ}$ and designed to assess the propagation of rainfall signals to the lee of the TP. The remaining two bands were 114 $-117^{\circ} \mathrm{E}$ and $121-124^{\circ} \mathrm{E}$, used to examine rainfall distribu- tion further east over land as well as over the nearby ocean.

Figure 12 presents the Fourier decomposition of wave numbers 0 - 2 from the mean diurnal cycle of TRMM 3-h rainfall in May, 2002 - 2005, and Figs. 13 and 14 show the results for June and July. From eastern TP to about $110^{\circ} \mathrm{E}$, the gradual shift of the rainfall maximum towards a later time, from near 1000 UTC (1800 LST) to after 2100 UTC (0500 LST), is clear in May and June (Figs. 12 and 13). Over $109-112^{\circ} \mathrm{E}$, the maximum rainfall occurs near 0600 UTC (1400 LST) in June (Fig. 13d), consistent with the slower mean propagation speed and stronger daytime heating than in May (cf. Figs. 5a, b). In July, the propagation signal at $105-108^{\circ} \mathrm{E}$ shows up as a secondary peak (at 2100 UTC), compared to a slightly higher primary peak in the afternoon (Fig. 14c), also in good agreement with Fig. 5c and Wang et al. (2005, their Figs. 11 and 12). The Hovmöller plot for August exhibits rainfall characteristics similar to those in 
July, and are not shown here.

For the CWB NFS 12 - $36 \mathrm{~h}$ QPFs (at 3-h intervals) from both 0000 and 1200 UTC model runs, the Fourier decomposition results are shown in Figs. 15 to 17 for May to July, respectively. Again, compared to TRMM data, the downstream shift of rainfall signals with time to the lee of the TP $\left(100-110^{\circ} \mathrm{E}\right)$ is vague in model forecasts. Throughout the warm season, the model produces too much rain
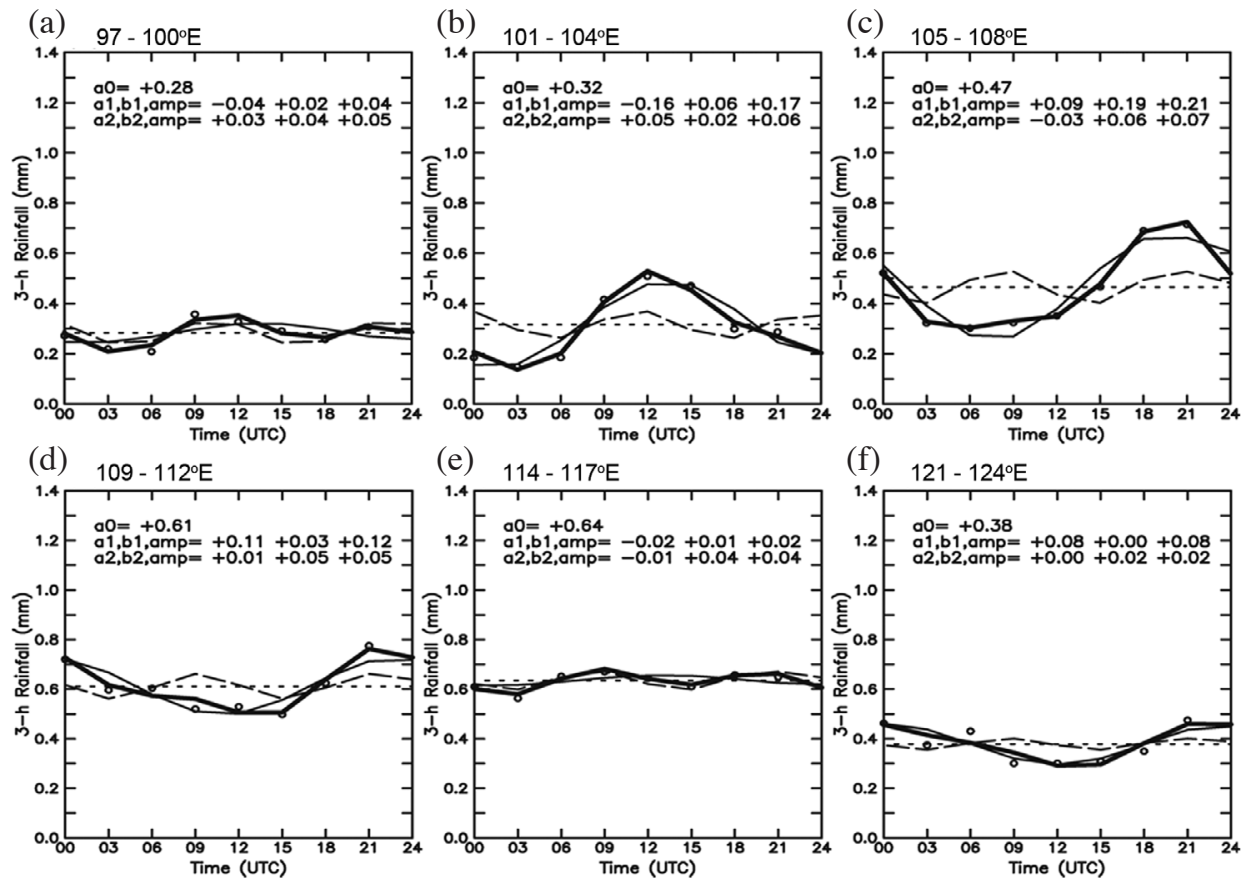

Fig. 12. Fourier decomposition (wave numbers 0 - 2) of mean diurnal cycle of TRMM 3-h rainfall (mm) in May, 2002 - 2005 , for the longitudinal bands (each $3^{\circ}$ in width) at (a) $97-100^{\circ} \mathrm{E}$, (b) $101-104^{\circ} \mathrm{E}$, (c) $105-108^{\circ} \mathrm{E}$, (d) $109-112^{\circ} \mathrm{E}$, (e) $114-117^{\circ} \mathrm{E}$, and (f) $121-124^{\circ} \mathrm{E}$. Dotted, thin solid, dashed, and thick solid lines represent wave numbers $0,1,2$, and their summation, respectively, and open circles depict original data before decomposition. The mean value (wave 0 ) and coefficients and amplitude (for waves 1 - 2) are listed.
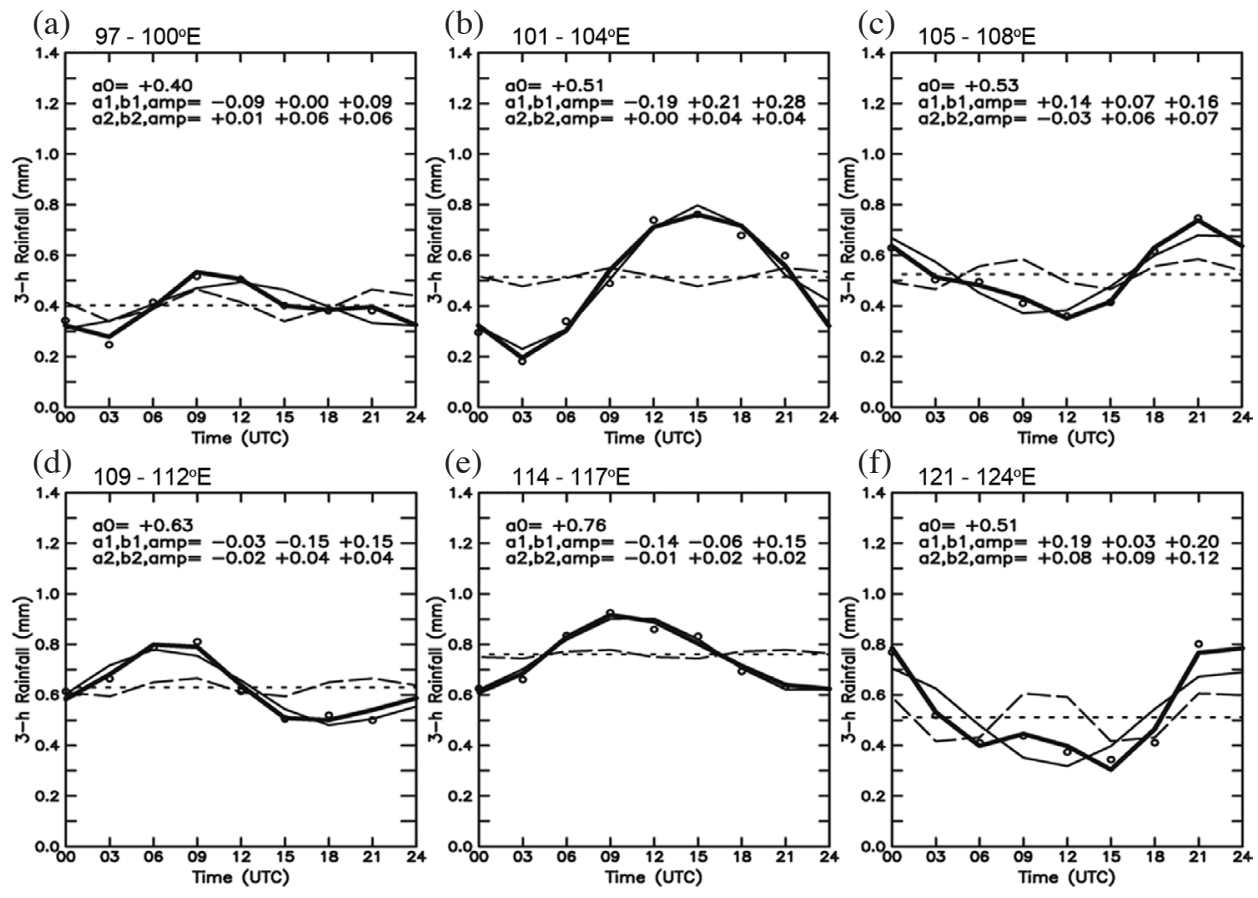

Fig. 13. Same as Fig. 12, except for June, 2002 - 2005. 
(in the mean value, i.e., wave 0) over the eastern TP (97 - $100^{\circ} \mathrm{E}$, Figs. $12 \mathrm{a}$ to $17 \mathrm{a}$ ) as discussed. At $101-104^{\circ} \mathrm{E}$, a similar but less serious over-prediction also occurs while the amplitude of diurnal signal (wave 1) is too large in May (Figs. $12 \mathrm{~b}$ and $15 \mathrm{~b}$ ). To the leeside at $105-108^{\circ} \mathrm{E}$, on the other hand, the amplitude of model diurnal wave is much too small although the phase (peaking near 2100 UTC) is correct (Figs. 12c and 15c). In both June and July, the observed peak time of the diurnal signal at $101-104^{\circ} \mathrm{E}$ is at 1500 UTC (Figs. 13b and 14b), but the forecast phase occurs too early (by roughly $4 \mathrm{~h}$ ) and the peak remains in late afternoon-early evening (Figs. 16b and 17b). Similarly, at
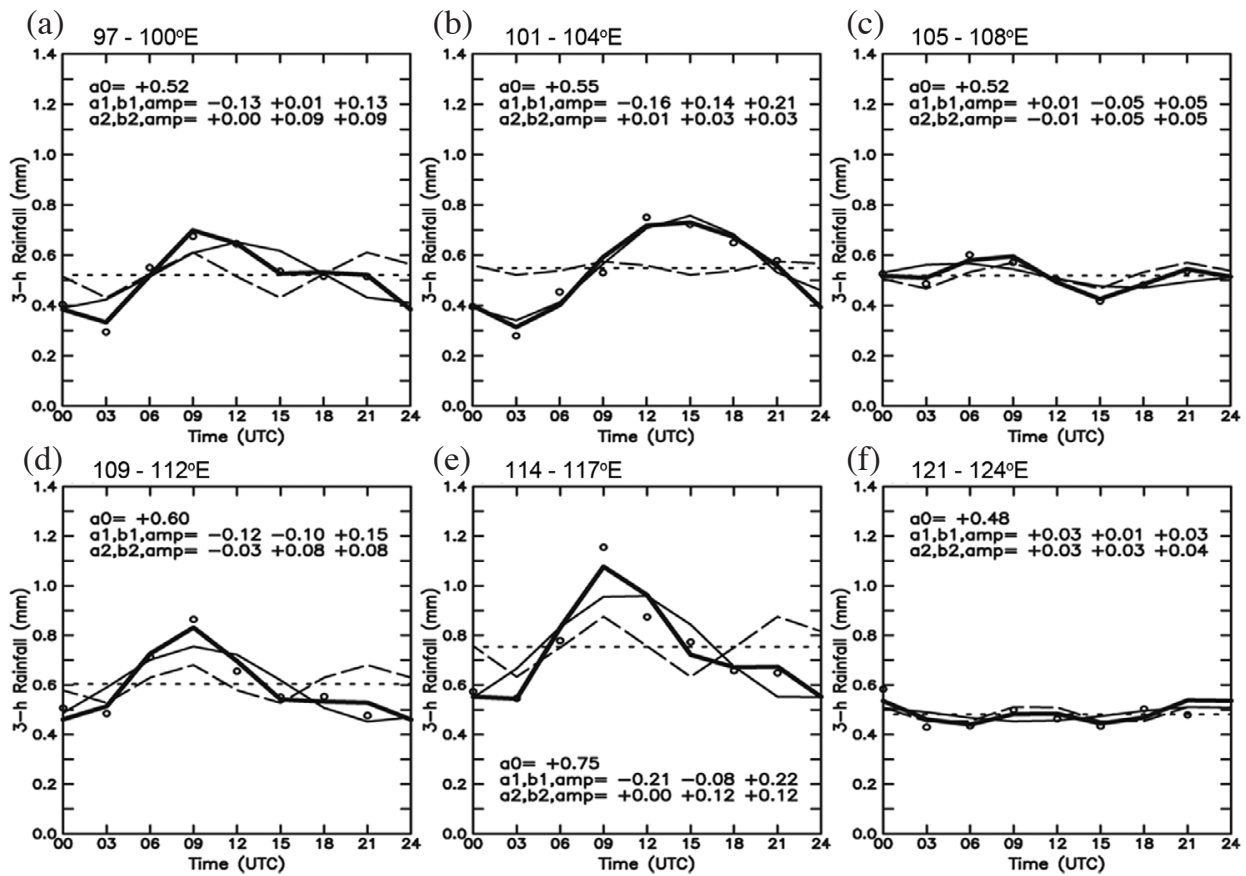

Fig. 14. Same as Fig. 12, except for July, 2002 - 2005.
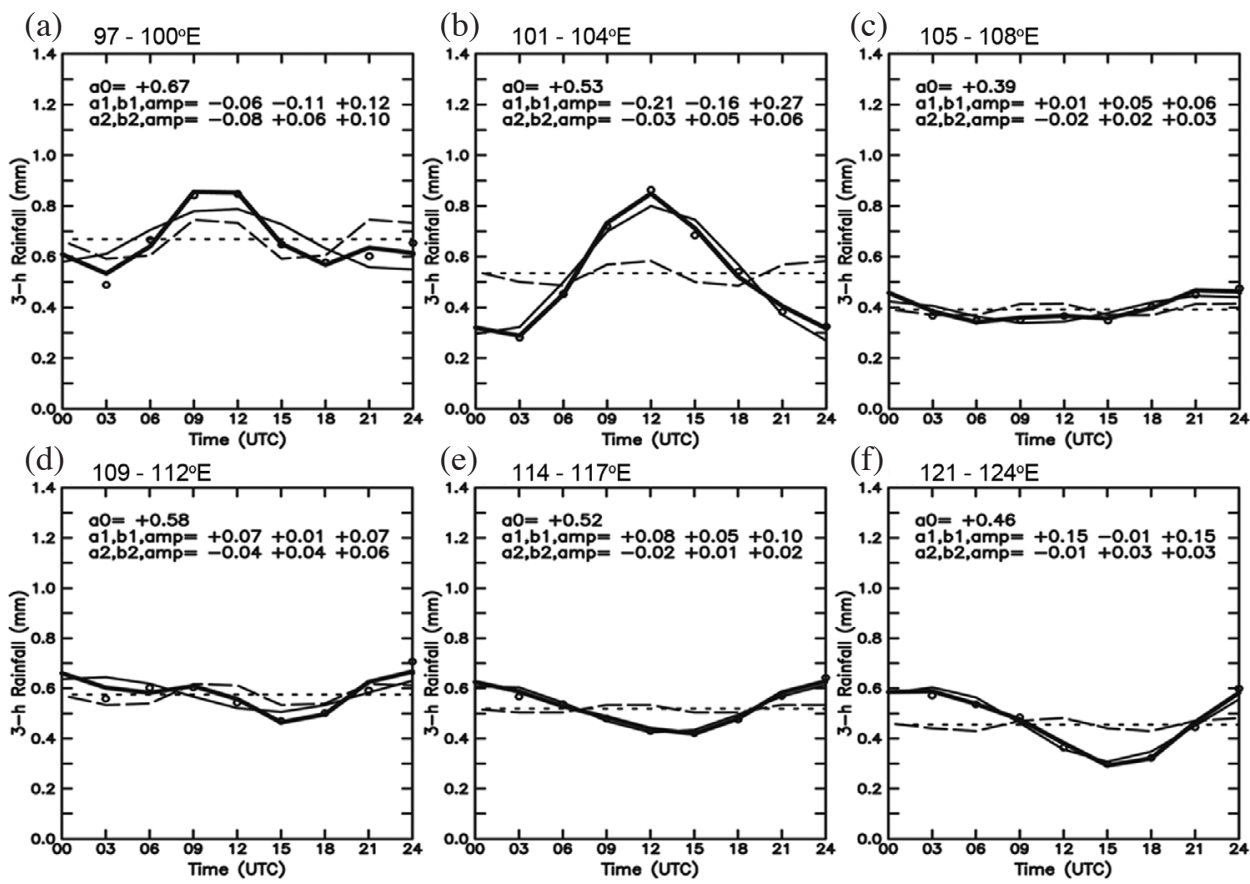

Fig. 15. Same as Fig. 12, but from the CWB NFS D1 (45 km) 12 - 36 h QPFs (mm) at 3-h intervals for May, 2002 - 2005. Both the runs at 0000 and 1200 UTC are used. 

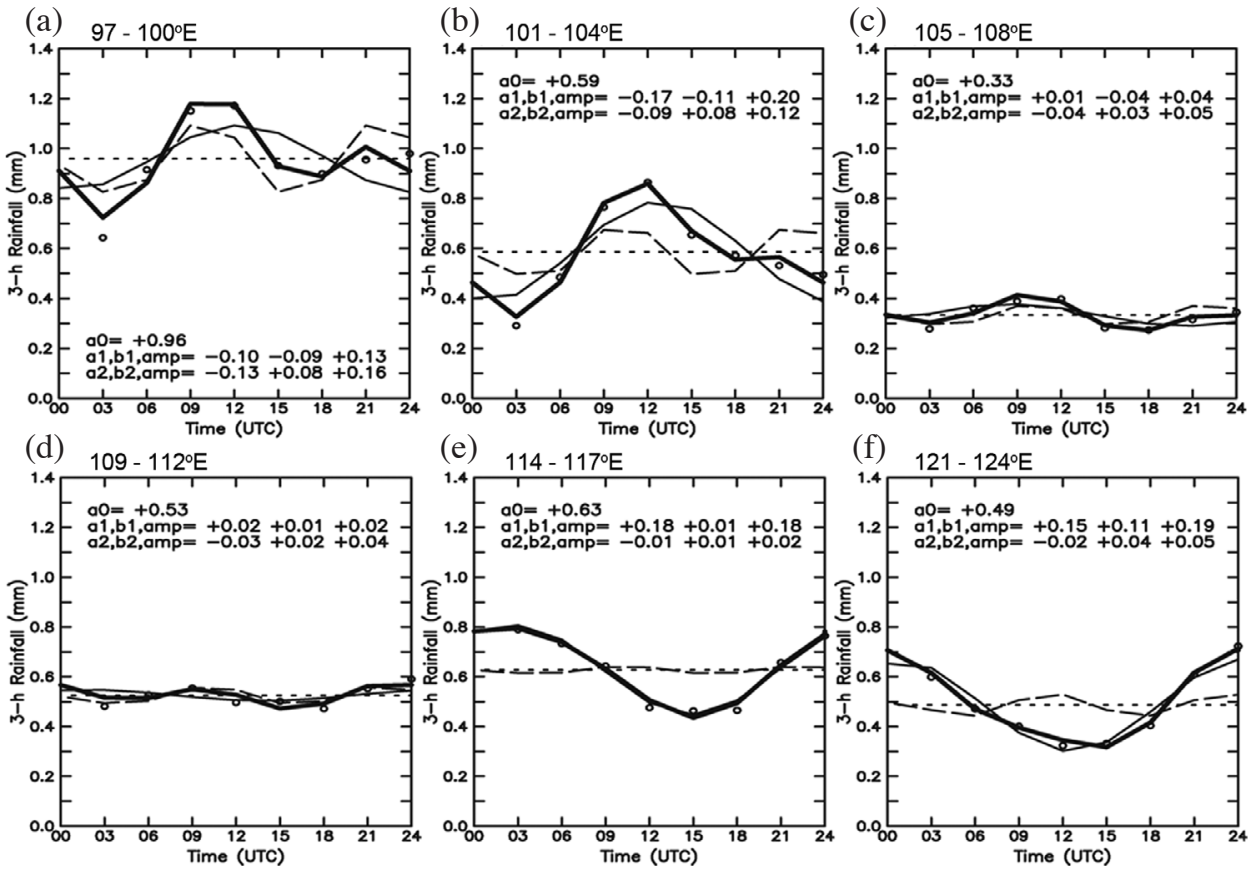

Fig. 16. Same as Fig. 15, except for June, 2002 - 2005.
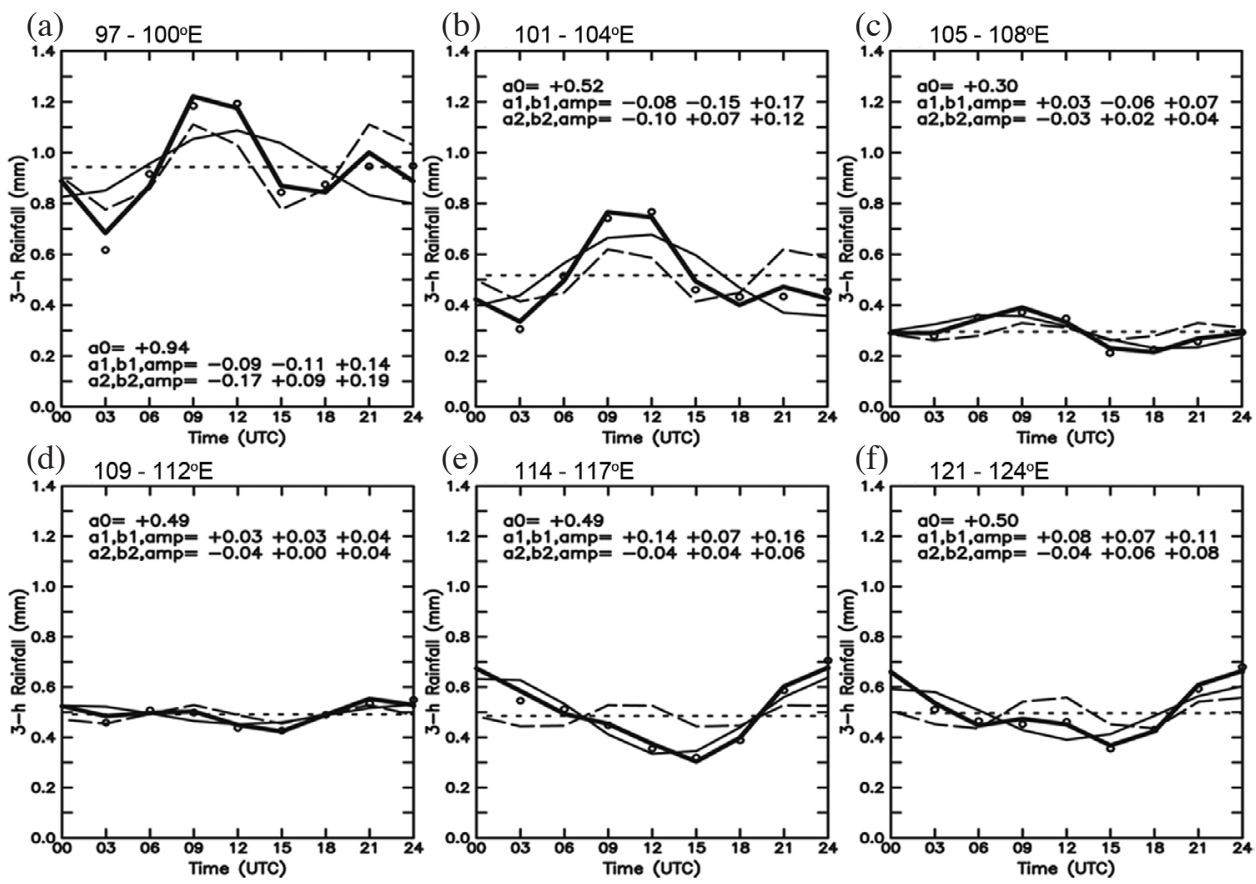

Fig. 17. Same as Fig. 15, except for July, 2002 - 2005.

$105-108^{\circ} \mathrm{E}$, the phase of the diurnal wave is also incorrect for June (peaking at 2100 UTC in TRMM but at 0900 UTC in NFS), and both its amplitude and the total amount are seriously under-predicted (Figs. 13c and 16c). In July, however, since the propagation signal also becomes a secondary peak in TRMM data, the under-prediction in amplitude appears less serious (Figs. 14c and 17c).
Further downstream at $109-112^{\circ} \mathrm{E}$, the rainfall peaks in the afternoon at 0600 - 0900 UTC (1400 - 1700 LST) in June and July with a clear diurnal cycle, but the NFS forecasts showed a very small amplitude with less amount (Figs. 13d, 14d, 16d, and 17d). At $114-117^{\circ} \mathrm{E}$, the modeled diurnal cycle (peak near 0000 UTC) is out-of-phase from the observation (peak at 0900 UTC) through much of the 
summer, while the two are nearly in-phase over the nearby ocean $\left(121-124^{\circ} \mathrm{E}\right)$. From Figs. 5, 6, and 11, it is clear that the phase error occurs consistently over a wide longitudinal range, roughly over $110-120^{\circ} \mathrm{E}$, and persists throughout the mid-summer.

The major results of the harmonic analysis are summarized in Table 2 for the first three harmonics (wave numbers 0 - 2) and in Table 3 for the diurnal wave (wave number 1), together with the forecast errors. Here, the peak time (of waves 0 - 2 or wave 1 , in LST) is estimated to the closest hour based on the shape of the curves, and the phase error is considered positive (negative) if the model rainfall peaks later (earlier) than the observation. For the mean 3-h rainfall (i.e., wave 0 ) value (Table 2 ) and the amplitude of wave 1 (Table 3), forecast errors are measured through relative error $(R E)$, defined as

$R E=\frac{A_{F}-A_{O}}{A_{O}}$

where $A_{F}$ and $A_{O}$ are the forecast and observed value, respectively. Thus, positive (negative) $R E$ values indicate over-forecast (under-forecast).

In Table 2, it can be seen that the NFS seriously overpredicts the total rainfall at $97-100^{\circ} \mathrm{E}$, with an excess of

Table 2. Mean value (i.e., wave $0, \mathrm{~mm}$ ) and peak time (LST) of the first three harmonics (waves 0 - 2) of the averaged diurnal cycle from TRMM 3-h rainfall (top) and NFS D1 3-h QPFs (middle) at the six longitudinal bands (each $3^{\circ}$ in width) from May to Aug, 2002 - 2005. The peak time is estimated to the closest hour based on the shape of the curves, and an asterisk denotes that the peak corresponding to the propagation signal is a secondary peak. The relative error in mean value (see text for details) and the error in peak time of the forecasts are given at the bottom. For the peak time error, positive (negative) values indicate that the model rainfall peaks later (earlier) than the observation. The values are given in bold face with gray background if the relative error is greater than $\pm 1 / 3$ or the peak time error is at least $\pm 6 \mathrm{~h}$.

\begin{tabular}{|c|c|c|c|c|c|c|c|}
\hline Longitudinal bands $\left({ }^{\circ} \mathbf{E}\right)$ & & $\begin{array}{c}1 \\
(97-100)\end{array}$ & $\begin{array}{c}2 \\
(101-104)\end{array}$ & $\begin{array}{c}3 \\
(105-108)\end{array}$ & $\begin{array}{c}4 \\
(109-112)\end{array}$ & $\begin{array}{c}5 \\
(114-117)\end{array}$ & $\begin{array}{c}6 \\
(121-124)\end{array}$ \\
\hline \multicolumn{8}{|l|}{ TRMM 3-h rainfall } \\
\hline \multirow[t]{4}{*}{ Mean value (wave 0) $(\mathrm{mm})$} & May & 0.28 & 0.32 & 0.47 & 0.61 & 0.64 & 0.38 \\
\hline & Jun & 0.40 & 0.51 & 0.53 & 0.63 & 0.76 & 0.51 \\
\hline & Jul & 0.52 & 0.55 & 0.52 & 0.60 & 0.75 & 0.48 \\
\hline & Aug & 0.45 & 0.52 & 0.48 & 0.54 & 0.61 & 0.64 \\
\hline \multirow[t]{4}{*}{ Peak time of waves 0 - 2 (LST) } & May & 19 & 20 & 04 & 06 & 17 & 07 \\
\hline & Jun & 18 & 23 & 05 & 15 & 18 & 07 \\
\hline & Jul & 18 & 22 & $05 *$ & 17 & 18 & 06 \\
\hline & Aug & 18 & 00 & $05 *$ & 17 & 17 & 06 \\
\hline \multicolumn{8}{|l|}{ NFS 3-h QPF } \\
\hline \multirow[t]{4}{*}{ Mean value (wave 0) (mm) } & May & 0.67 & 0.53 & 0.39 & 0.58 & 0.52 & 0.46 \\
\hline & Jun & 0.96 & 0.59 & 0.33 & 0.53 & 0.63 & 0.49 \\
\hline & Jul & 0.94 & 0.52 & 0.30 & 0.49 & 0.49 & 0.50 \\
\hline & Aug & 0.59 & 0.44 & 0.37 & 0.50 & 0.44 & 0.65 \\
\hline \multirow[t]{4}{*}{ Peak time of waves 0 - 2 (LST) } & May & 19 & 20 & 07 & 07 & 08 & 11 \\
\hline & Jun & 19 & 19 & 17 & 07 & 11 & 08 \\
\hline & Jul & 18 & 18 & 17 & 05 & 08 & 08 \\
\hline & Aug & 18 & 19 & $06 *$ & 08 & 08 & 08 \\
\hline \multicolumn{8}{|l|}{ Forecast error } \\
\hline \multirow[t]{4}{*}{ Relative error in mean (wave 0) } & May & 1.39 & 0.66 & -0.17 & -0.05 & -0.19 & 0.21 \\
\hline & Jun & 1.40 & 0.16 & -0.38 & -0.16 & -0.17 & -0.04 \\
\hline & Jul & 0.81 & -0.05 & -0.42 & -0.18 & -0.35 & 0.04 \\
\hline & Aug & 0.31 & -0.15 & -0.23 & -0.07 & -0.28 & 0.02 \\
\hline \multirow[t]{4}{*}{ Error in peak time of waves 0 - 2 (h) } & May & 0 & 0 & +3 & +1 & -9 & +4 \\
\hline & Jun & +1 & -4 & -12 & -8 & -7 & +1 \\
\hline & Jul & 0 & -4 & -12 & -12 & -10 & +2 \\
\hline & Aug & 0 & -5 & +1 & -9 & -9 & +2 \\
\hline
\end{tabular}


Table 3. Same as Table 2, but for the amplitude (mm) and peak time (LST) of the diurnal wave (i.e., wave 1) of the averaged diurnal cycle from TRMM 3-h rainfall (top) and NFS D1 3-h QPF (middle) at the six longitudinal bands from May to Aug, 2002 - 2005. The relative error in the amplitude and the error in peak time (both of wave 1) of the forecasts are also given at the bottom, in the same way as in Table 2.

\begin{tabular}{|c|c|c|c|c|c|c|c|}
\hline Longitudinal bands $\left({ }^{\circ} \mathbf{E}\right)$ & & $\begin{array}{c}1 \\
(97-100)\end{array}$ & $\begin{array}{c}2 \\
(101-104)\end{array}$ & $\begin{array}{c}3 \\
(105-108)\end{array}$ & $\begin{array}{c}4 \\
(109-112)\end{array}$ & $\begin{array}{c}5 \\
(114-117)\end{array}$ & $\begin{array}{c}6 \\
(121-124)\end{array}$ \\
\hline \multicolumn{8}{|l|}{ TRMM 3-h rainfall } \\
\hline \multirow[t]{4}{*}{ Amplitude of wave $1(\mathrm{~mm})$} & May & 0.04 & 0.17 & 0.21 & 0.12 & 0.02 & 0.08 \\
\hline & Jun & 0.09 & 0.28 & 0.16 & 0.15 & 0.15 & 0.20 \\
\hline & Jul & 0.13 & 0.21 & 0.05 & 0.15 & 0.22 & 0.03 \\
\hline & Aug & 0.13 & 0.18 & 0.08 & 0.15 & 0.18 & 0.12 \\
\hline \multirow[t]{4}{*}{ Peak time of wave 1 (LST) } & May & 22 & 21 & 04 & 07 & 22 & 08 \\
\hline & Jun & 20 & 23 & 06 & 14 & 18 & 08 \\
\hline & Jul & 20 & 23 & 12 & 17 & 19 & 06 \\
\hline & Aug & 21 & 00 & 14 & 17 & 18 & 08 \\
\hline \multicolumn{8}{|l|}{ NFS 3-h QPF } \\
\hline \multirow[t]{4}{*}{ Amplitude of wave $1(\mathrm{~mm})$} & May & 0.12 & 0.27 & 0.05 & 0.07 & 0.10 & 0.15 \\
\hline & Jun & 0.13 & 0.20 & 0.04 & 0.02 & 0.18 & 0.19 \\
\hline & Jul & 0.14 & 0.17 & 0.07 & 0.04 & 0.16 & 0.11 \\
\hline & Aug & 0.08 & 0.10 & 0.02 & 0.12 & 0.12 & 0.15 \\
\hline \multirow[t]{4}{*}{ Peak time of wave 1 (LST) } & May & 19 & 20 & 06 & 11 & 09 & 11 \\
\hline & Jun & 20 & 21 & 16 & 11 & 11 & 08 \\
\hline & Jul & 20 & 19 & 15 & 08 & 09 & 08 \\
\hline & Aug & 22 & 20 & 13 & 08 & 09 & 08 \\
\hline \multicolumn{8}{|l|}{ Forecast error } \\
\hline \multirow[t]{4}{*}{ Relative error in amplitude of wave 1} & May & 2.00 & 0.59 & -0.76 & -0.42 & 4.00 & 0.88 \\
\hline & Jun & 0.44 & -0.29 & -0.75 & -0.87 & 0.20 & -0.05 \\
\hline & Jul & 0.08 & -0.19 & 0.40 & -0.73 & -0.27 & 2.67 \\
\hline & Aug & -0.38 & -0.44 & -0.75 & -0.20 & -0.33 & 0.25 \\
\hline \multirow[t]{4}{*}{ Error in peak time of wave 1 (h) } & May & -3 & -1 & +2 & +4 & +11 & +3 \\
\hline & Jun & 0 & -2 & +10 & -3 & -7 & 0 \\
\hline & Jul & 0 & -4 & +3 & -9 & -10 & +2 \\
\hline & Aug & +1 & -4 & -1 & -9 & -9 & 0 \\
\hline
\end{tabular}

nearly 1.4 times the observed amount in May - June. Over $101-104^{\circ} \mathrm{E}$, the rainfall is also over-predicted for May. From $105^{\circ} \mathrm{E}$ to about $120^{\circ} \mathrm{E}$ (bands $3-5$ ), in contrast, the NFS consistently produces not enough rain, especially over $105-108^{\circ} \mathrm{E}$ in June - July as well as over $114-117^{\circ} \mathrm{E}$ in July when the model rainfall is less than $2 / 3$ of the observed amount. These results are consistent with the overall decrease in ETS and BS values (at the lowest threshold for ETS) from $95-100^{\circ} \mathrm{E}$ to $105-110^{\circ} \mathrm{E}$, as shown in Fig. 18. In Table 2 for June and July, to the lee of the TP (bands 2 - 4), the gradual shift of the peak time (of waves $0-2$ ) toward the east, in accordance to the downstream propagation of signals, is evident in the TRMM data but not in the NFS QPFs. Thus, the modeled rainfall peaks increasingly too early, to almost out-of-phase from the observation east of $105^{\circ} \mathrm{E}$. On the other hand, the phase of waves $0-2$ is roughly correct over bands 2 - 4 in May, indicating a better performance by the model (cf. Fig. 8). Qualitatively, similar results can be obtained by comparing Figs. 5 and 6, and are anticipated since synoptic-scale forcing tends to have more control over rainfall events early in the warm season in May.

The forecast errors seen in Table 2 are largely related and perhaps can be attributed to the errors in phase and amplitude of the diurnal component of rainfall. As shown in Table 3, the NFS tends to over-predict the amplitude of wave 1 when the observed amplitude is small (say, $\leq 0.05$ $\mathrm{mm}$ ). Apart from such influences, the tendency for NFS to under-predict the amplitude of wave 1 over bands 2 to 4 is quite evident after May, by typically 25 - 75\% (Table 3). 
From 101 to $112^{\circ} \mathrm{E}$, the phase of the diurnal wave (timing of the peak) also consistently shifts later toward the east in all four months in the TRMM data (similar to the phase of waves 0 - 2 in Table 2), but not so in the model. Again, the phase error for wave 1 is at least $7 \mathrm{~h}$ at band 5 but within $3 \mathrm{~h}$ at band 6 throughout the period of May - August (Table 3).

The results of harmonic analysis for 0000 and 1200 UTC model runs are compared at bands 1 - 4 for June in
Fig. 19 and summarized for May and June in Table 4. For bands 1 - 3, from the eastern TP to its immediate lee, although the 1200 UTC runs produce less total rainfall in June (as well as in other warm-season months), it is clear that such a tendency exists only during daytime (0300 - 1200 UTC) while the opposite is true during the night (at 1500 2400 UTC, Figs. 19a - c, e - g). In other words, in a relative sense, the 0000 UTC model runs tend to produce more rain-
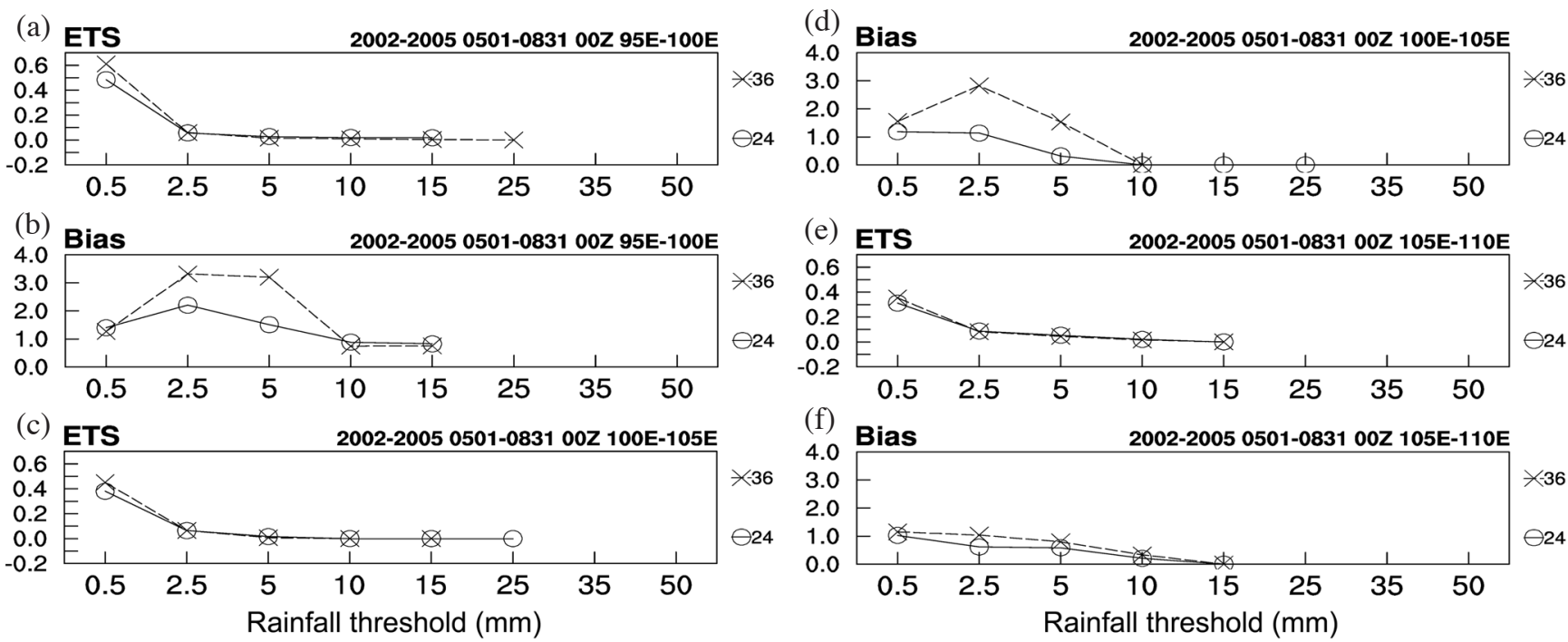

Fig. 18. (a) (b) Same as Figs. 2a, b, except for 12-h QPFs from the 0000 UTC runs at forecast ranges of 12 - 24 (circle) and 24 - $36 \mathrm{~h}$ (cross) for the longitudinal bands of $95-100^{\circ} \mathrm{E}$. (c) (d) and (e) (f) Same as (a) (b), but for $100-105^{\circ} \mathrm{E}$ and $105-110^{\circ} \mathrm{E}$, respectively.
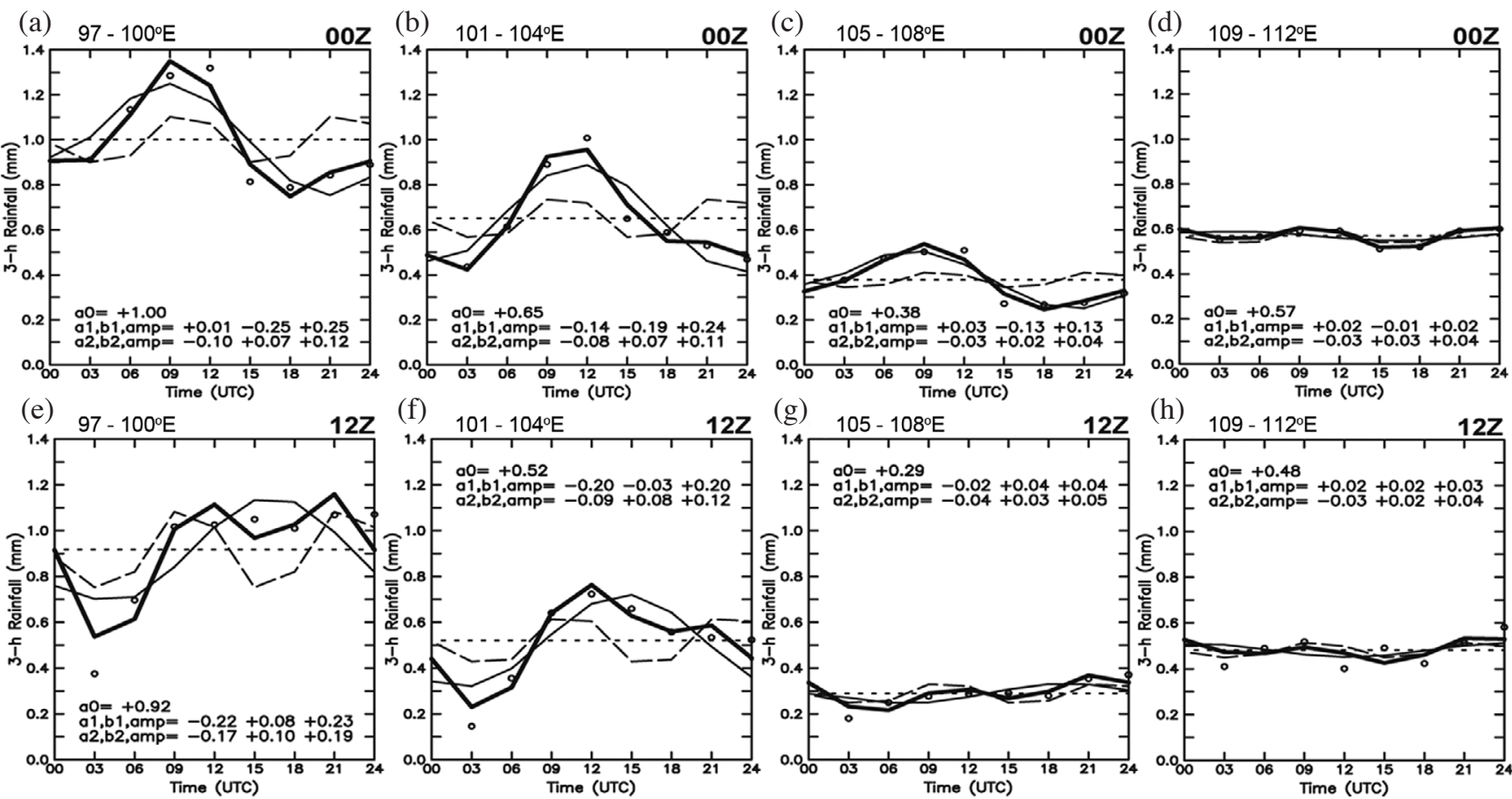

Fig. 19. (a) - (d) Same as Figs. 15a - d, except from only the 0000 UTC runs of the CWB NFS D1 12 - 36 h QPFs (mm) at 3-h intervals for June, 2002 - 2005, for the longitudinal bands at (a) $97-100^{\circ} \mathrm{E}$, (b) $101-104^{\circ} \mathrm{E}$, (c) $105-108^{\circ} \mathrm{E}$, and (d) $109-112^{\circ} \mathrm{E}$. (e) - (h) Same as (a) - (d), except from only the 1200 UTC runs. 
Table 4. Same as Table 2, except for the mean value (wave 0, mm) and peak time (LST) of the first three harmonics (waves 0 - 2) and their forecast errors from only the 0000 (top) and 1200 UTC runs (bottom) of NFS D1 3-h QPF at May and Jun, 2002 - 2005.

\begin{tabular}{|c|c|c|c|c|c|c|c|}
\hline Longitudinal bands $\left({ }^{\circ} \mathbf{E}\right)$ & & $\begin{array}{c}1 \\
(97-100)\end{array}$ & $\begin{array}{c}2 \\
(101-104)\end{array}$ & $\begin{array}{c}3 \\
(105-108)\end{array}$ & $\begin{array}{c}4 \\
(109-112)\end{array}$ & $\begin{array}{c}5 \\
(114-117)\end{array}$ & $\begin{array}{c}6 \\
(121-124)\end{array}$ \\
\hline \multicolumn{8}{|l|}{ NFS 3-h QPF of 0000 UTC runs } \\
\hline \multirow{2}{*}{ Mean value (wave 0) $(\mathrm{mm})$} & May & 0.67 & 0.57 & 0.40 & 0.60 & 0.55 & 0.49 \\
\hline & Jun & 1.00 & 0.65 & 0.38 & 0.57 & 0.66 & 0.51 \\
\hline \multirow[t]{2}{*}{ Peak time of waves 0 - 2 (LST) } & May & 18 & 20 & 10 & 15 & 08 & 10 \\
\hline & Jun & 17 & 19 & 17 & 18 & 10 & 08 \\
\hline \multicolumn{8}{|l|}{ Forecast error of 0000 UTC runs } \\
\hline \multirow[t]{2}{*}{ Relative error in mean (wave 0) } & May & 1.39 & 0.78 & -0.15 & -0.02 & -0.14 & 0.29 \\
\hline & Jun & 1.50 & 0.27 & -0.28 & -0.10 & -0.13 & 0.00 \\
\hline \multirow[t]{2}{*}{ Error in peak time of waves 0 - $2(h)$} & May & -1 & 0 & +6 & +9 & -9 & +3 \\
\hline & Jun & -1 & -4 & -12 & +3 & -8 & +1 \\
\hline \multicolumn{8}{|l|}{ NFS 3-h QPF of 1200 UTC runs } \\
\hline \multirow[t]{2}{*}{ Mean value (wave 0) (mm) } & May & 0.66 & 0.50 & 0.39 & 0.55 & 0.49 & 0.42 \\
\hline & Jun & 0.92 & 0.52 & 0.29 & 0.48 & 0.59 & 0.46 \\
\hline \multirow[t]{2}{*}{ Peak time of waves 0 - 2 (LST) } & May & 19 & 20 & 05 & 07 & 09 & 14 \\
\hline & Jun & 05 & 20 & 05 & 06 & 11 & 08 \\
\hline \multicolumn{8}{|l|}{ Forecast error of 1200 UTC runs } \\
\hline \multirow[t]{2}{*}{ Relative error in mean (wave 0) } & May & 1.36 & 0.56 & -0.17 & -0.10 & -0.23 & 0.11 \\
\hline & Jun & 1.30 & 0.02 & -0.45 & -0.24 & -0.22 & -0.10 \\
\hline \multirow[t]{2}{*}{ Error in peak time of waves 0 - 2 (h) } & May & 0 & 0 & +1 & +1 & -8 & +7 \\
\hline & Jun & +11 & -3 & 0 & -9 & -7 & +1 \\
\hline
\end{tabular}

fall during the day (near 0900 - 1200 UTC), and the 1200 UTC runs at nights (near 2100 UTC). This phenomenon can be seen in Figs. 6 and 11 (west of $110^{\circ} \mathrm{E}$ ), and suggests that the rainfall systems in the NFS D1 domain tend to be better developed near $30 \mathrm{~h}$ into the forecast, i.e., toward the end of the 12 - $36 \mathrm{~h}$ period for runs at both initial times, consistent with the increase in BS toward longer ranges (cf. Fig. 2). The rainfall near 2100 UTC leads to a double peaked structure for bands 1 - 3 for 1200 UTC runs in June (Figs. 19e - g), and coincides with the observed propagation signal at 105 $108^{\circ} \mathrm{E}$ (cf. Fig. 5b). Although this nocturnal peak at band 3 is correct in its phase (while a similar peak does not exist in 0000 UTC runs, see also Table 4), both the total rainfall and the amplitude of the diurnal cycle are too small (Fig. 19g, cf. Fig. 13c). Thus, the propagation of rainfall signals to the lee is still not well captured in the 1200 UTC runs. Over $109-112^{\circ} \mathrm{E}$, the amplitude of diurnal cycle remains small in both 0000 and 1200 UTC model runs (Figs. 19d, h, cf. Fig. 13d).

In addition, Table 4 indicates that the over-prediction in total rainfall near the eastern TP (bands 1 - 2) does improve to some extent in the 1200 UTC runs compared to the 0000 UTC runs, by $3-25 \%$, in agreement with Fig. 18 . However, from $105-120^{\circ} \mathrm{E}$, the under-prediction for rain- fall also inevitably becomes more serious (by 2 - 17\%) in 1200 UTC model runs, especially in June at band 3. Over $114-117^{\circ} \mathrm{E}$, again, the phase for waves $0-2$ is still incorrect while the total rainfall is also somewhat under-predicted (by about $10-20 \%$ ). A comparison between the results in May and June confirms that the model indeed performed slightly better in May for both 0000 and 1200 UTC runs (cf. Fig. 8), apart from the more serious over-prediction in total rainfall for band 2 .

\section{DISCUSSION AND CONCLUSION}

Through the use of the TRMM 3B42 merged satellite rain-rates (at $0.25^{\circ} \times 0.25^{\circ}$ and 3 -h resolution) as observations, the 12 - $36 \mathrm{~h}$ coarse domain (at a grid spacing of $45 \mathrm{~km}$ ) QPFs of the regional operational model in Taiwan, i.e., the CWB NFS (also every $3 \mathrm{~h}$ ) is evaluated, mainly for its performance in capturing the eastward (downstream) propagation of rainfall signals to the lee of the TP over the East Asian continent (inside $25-40^{\circ} \mathrm{N}, 95-125^{\circ} \mathrm{E}$ ) during the warm season (May - August) of 2002 - 2005.

Although the NFS D1 QPFs generally agree with the observations in the basic distribution and episodic characteristics of rainfall in the study region, the propagation sig- 
nals in the mean diurnal cycle were poorly captured in the model throughout the warm season, with an ETS score near or below 0.2 . With a nocturnal rainfall peak over the SB area, such signals are evident and can reach about $118^{\circ} \mathrm{E}$ in the TRMM data in May - June, but their counterparts in the NFS is unclear and confined to the west of $110^{\circ} \mathrm{E}$ in May and even west of $105^{\circ} \mathrm{E}$ in June. In mid-summer (July - August) when the propagation signals also weaken but still discernable (to about $110^{\circ} \mathrm{E}$ ) in the observation, they were almost completely missing in the model results. Overall, model QPFs show the largest disagreement with TRMM rain-rates in June, and the least in May. The above results are similar to those obtained previously for the US Great Plains by Davis et al. (2003), who concluded that the lack of propagation is due to inadequate model resolution and the use of the CPS. When the internal structure of the MCSs, specifically the cold-pool, is not resolved (or adequately represented) in the model, there is a lack of the self-propagation mechanism in a sheared environment (e.g., Rotunno et al. 1988) and this discrepancy arises. This is clearly the case of the NFS coarse domain at a grid spacing of $45 \mathrm{~km}$. To better represent organized convection in models with intermediate resolution (about $10 \mathrm{~km}$ ), for example, Moncrieff and Liu (2006) proposed a hybrid strategy to include the effects of stratiform heating and mesoscale downdraft in addition to those included by a contemporary CPS.

Over the eastern TP, the NFS tends to predict too much rain in May-June, with an excess up to 1.4 times the observed amount and a higher BS score. To the leeside (up to about $110^{\circ} \mathrm{E}$ ), in contrast, the model usually predicts not enough rain with diurnal signals too small in amplitude (by about $1 / 4$ to $3 / 4$ ), especially after May when the peak time remains in late afternoon and does not shift toward a later time downstream as observed. The over- and under-prediction of rain at eastern TP and its lee can be partially attributed to the lack of eastward propagation of rainfall systems out from the plateau. Besides the above deficiency in capturing the propagation signals and the nocturnal peak near the $\mathrm{SB}$ area, a phase error by at least $\pm 7 \mathrm{~h}$ in rainfall also occurs persistently in the NFS QPFs over $110-120^{\circ} \mathrm{E}$ (peaking in the afternoon in TRMM but morning in the model) for much of the warm season since mid-June. This most likely points to a systematic delay in the development of rain-producing systems in this region, possibly related to spin-up problems in the model.

Compared to 0000 UTC runs, the 1200 UTC runs of the NFS overall produce less rainfall for most regions inside the study domain. Therefore, the over-prediction at the eastern TP is less serious, but the under-prediction to the lee (to about $110^{\circ} \mathrm{E}$ ) is more. It is also found that rainfall systems tend to be better developed near $30 \mathrm{~h}$ into the forecast in runs at both initial times, i.e., toward the end of the $12-36 \mathrm{~h}$ forecast range used here. Also manifested as an increase in BS values, this tendency of the NFS to become more rainy with time is most likely due to issues in the Kuo-type CPS or other physical parameterization. From the 2002 to 2004 season, although still inadequate, the NFS showed slight improvement in capturing the propagation signals to the lee of the TP, and the QPFs also became finer with more details. However, the phase error of rainfall over $110-120^{\circ} \mathrm{E}$ persisted throughout the four warm seasons studied.

Acknowledgements The authors wish to thank Dr. MongMing Lu of the CWB and another anonymous reviewer for their helpful comments. The assistance from Ms. Yi-Wen Wang in the calculation of skill scores and Ms. Yun-Wei Huang in figure editing is appreciated. This study was jointly supported by the National Science Council of Taiwan under NSC-96-2111-M-002-010-MY3, NSC-97-2111-M003-005-MY2, NSC-99-2111-M-003-004-MY3, and NSC99-2111-M-002-001, and by the National Taiwan University (NTU) under Grant 99R40044.

\section{REFERENCES}

Ahijevych, D. A., C. A. Davis, R. E. Carbone, and J. D. Tuttle, 2004: Initiation of precipitation episodes relative to elevated terrain. J. Atmos. Sci., 61, 2763-2769, doi: 10.1175/JAS3307.1. [Link]

Arakawa, A. and W. H. Schubert, 1974: Interaction of a cumulus cloud ensemble with the large-scale environment, Part I. J. Atmos. Sci., 31, 674-701, doi: 10.1175/1 520-0469(1974)031<0674:IOACCE>2.0.CO;2. [Link]

Asai, T., S. Ke, and Y.-M. Kodama, 1998: Diurnal variability of cloudiness over East Asia and the Western Pacific Ocean as revealed by GMS during the warm season. $J$. Meteorol. Soc. Jpn., 76, 675-684.

Augustine, J. A., 1984: The diurnal variation of large-scale inferred rainfall over the tropical Pacific Ocean during August 1979. Mon. Weather Rev., 112, 1745-1751, doi: 10.1175/1520-0493(1984)112<1745:TDVOLS $>2.0$. $\mathrm{CO} ; 2 .[\underline{\mathrm{Link}}]$

Barker, E. H., 1992: Design of the Navy's multivariate optimum interpolation analysis system. Weather Forecast., 7, 220-231, doi: 10.1175/1520-0434(1992)007<0 220:DOTNMO>2.0.CO;2. [Link]

Barros, A. P., G. Kim, E. Williams, and S. W. Nesbitt, 2004: Probing orographic controls in the Himalayas during the monsoon using satellite imagery. Nat. Hazards Earth Syst. Sci., 4, 29-51.

Carbone, R. E., J. D. Tuttle, D. A. Ahijevych, and S. B. Trier, 2002: Inferences of predictability associated with warm season precipitation episodes. J. Atmos. Sci., 59, 2033-2056, doi: 10.1175/1520-0469(2002)059<2033:I OPAWW>2.0.CO;2. [Link]

Chen, D.-S., K.-N. Huang, and T.-C. Yeh, 2005: A study on typhoon track forecast for the Non-hydrostatic Forecast System of the Central Weather Bureau. Meteor. 
Bull., 45, 25-44. (in Chinese)

Chen, G. T.-J., S. L. Shieh, L. F. Chen, and C. D. Chen, 1991: On the forecast skill of heavy rainfall in Taiwan. Atmos. Sci., 19, 177-188. (in Chinese)

Chien, F. C. and B. J. D. Jou, 2004: MM5 ensemble mean precipitation forecasts in the Taiwan area for three early summer convective (Mei-Yu) seasons. Weather Forecast., 19, 735-750, doi: 10.1175/1520-0434(2004) 019<0735:MEMPFI>2.0.CO;2. [Link]

Chien, F. C., Y. H. Kuo, and M. J. Yang, 2002: Precipitation forecast of MM5 in the Taiwan area during the 1998 Mei-yu season. Weather Forecast., 17, 739-754, doi: 10.1175/1520-0434(2002)017<0739:PFOMIT>2.0. CO;2. [Link]

Dai, A., F. Giorgi, and K. E. Trenberth, 1999: Observed and model-simulated diurnal cycles of precipitation over the contiguous United States. J. Geophys. Res., 104, 6377-6402, doi: 10.1029/98JD02720. [Link]

Davis, C. A., K. W. Manning, R. E. Carbone, S. B. Trier, and J. D. Tuttle, 2003: Coherence of warm-season continental rainfall in numerical weather prediction models. Mon. Weather Rev., 131, 2667-2679, doi: 10.1 175/1520-0493(2003)131<2667:COWCRI>2.0.CO;2. [Link]

Davis, C. A., B. Brown, and R. Bullock, 2006: Object-based verification of precipitation forecasts. Part I: Methodology and application to mesoscale rain areas. Mon. Weather Rev., 134, 1772-1784, doi: 10.1175/MWR31 45.1. [Link]

Detering, H. W. and D. Etling, 1985: Application of the E- $\varepsilon$ turbulence model to the atmosphere boundary layer. Bound.-Layer Meteor., 33, 113-133.

Fritsch, M. J. and R. E. Carbone, 2004: Improving quantitative precipitation forecasts in the warm season: A USWRP research and development strategy. Bull. Amer. Meteorol. Soc., 85, 955-965, doi: 10.1175/BAMS-857-955. [Link]

Fu, R., A. D. Del Genio, and W. B. Rossow, 1990: Behavior of deep convective clouds in the Tropical Pacific deduced from ISCCP radiances. J. Climate, 3, 11291152, doi: 10.1175/1520-0442(1990)003<1129:BODC CI>2.0.CO;2. [Link]

Goerss, J. S. and P. A. Phoebus, 1992: The Navy's operational atmospheric analysis. Weather Forecast., 7, 232249, doi: 10.1175/1520-0434(1992)007<0232:TNOA $\mathrm{A}>2.0 . \mathrm{CO} ; 2$. [Link]

Harshvardhan, R. Davies, D. A. Randall, and T. G. Corsetti, 1987: A fast radiation parameterization for atmospheric circulation models. J. Geophys. Res., 92, 1009-1016, doi: 10.1029/JD092iD01p01009. [Link]

Hong, J. S., 2002: The evaluation of typhoon track and quantitative precipitation forecasts of CWB's NFS in 2001. Meteor. Bull., 44, 41-53. (in Chinese)

Hong, J. S., 2003: Evaluation of the high-resolution model forecasts over the Taiwan area during GIMEX. Weather Forecast., 18, 836-846, doi: 10.1175/1520-0434 (2003)018<0836:EOTHMF>2.0.CO;2. [Link]

Huffman, G. J., D. T. Bolvin, E. J. Nelkin, D. B. Wolff, R. F. Adler, G. Gu, Y. Hong, K. P. Bowman, and E. F. Stocker, 2007: The TRMM multisatellite precipitation analysis (TMPA): Quasi-global, multiyear, combinedsensor precipitation estimates at fine scales. J. Hydrometeorol., 8, 38-55, doi: 10.1175/JHM560.1. [Link]

Johnson, R. H., 2010: Diurnal cycle of monsoon convection. In: Chang, C. P (Ed.), the Global Monsoon System, Research and Forecast, $2^{\text {nd }}$ Ed, World Scientific Publication Co., Singapore.

Kuo, H. L., 1974: Further studies of the parameterization of the influence of cumulus convection on large-scale flow. J. Atmos. Sci., 31, 1232-1240, doi: 10.1175/1520 -0469(1974)031<1232:FSOTPO>2.0.CO;2. [Link]

Kurosaki, Y. and F. Kimura, 2002: Relationship between topography and daytime cloud activity around Tibetan Plateau. J. Meteorol. Soc. Jpn., 80, 1339-1355, doi: 10.2151/jmsj.80.1339. [Link]

Leou, T. M. and C. S. Liu, 2001: A case analysis of NFS during SCSMEX. Proceeding, 2001 Conference on Weather Analysis and Forecasting, CWB, Taipei, Taiwan, 161-165. (in Chinese)

Lorenc, A. C., 1981: A global three-dimensional multivariate statistical interpolation scheme. Mon. Weather Rev., 109, 701-721, doi: 10.1175/1520-0493(1981)109 $<0701$ :AGTDMS>2.0.CO;2. [Link]

Moncrieff, M. W. and C. Liu, 2006: Representing convective organization in prediction models by a hybrid strategy. J. Atmos. Sci., 63, 3404-3420, doi: 10.1175/ JAS3812.1. [Link]

Murakami, M., 1983: Analysis of the deep convective activity over the western Pacific and Southeast Asia, Part I: Diurnal variation. J. Meteorol. Soc. Jpn., 61, 60-76.

Olson, D. A., N. W. Junker, and B. Korty, 1995: Evaluation of 33 years of quantitative precipitation forecasting at the NMC. Weather Forecast., 10, 498-511, doi: 10.1 175/1520-0434(1995)010<0498:EOYOQP>2.0.CO;2. [Link]

Rotunno, R., J. B. Klemp, and M. L. Weisman, 1988: A theory for strong, long-lived squall lines. J. Atmos. Sci., 45, 463-485, doi: 10.1175/1520-0469(1988)045<0463: ATFSLL>2.0.CO;2. [Link]

Sato, T., H. Miura, and M. Satoh, 2007: Spring diurnal cycle of clouds over Tibetan Plateau: Global cloud-resolving simulations and satellite observations. Geophys. Res. Lett., 34, L18816, doi: 10.1029/2007GL030782. [Link]

Seng, Y. F., S. C. Lin, T. M. Leou, S. C. Lin, and C. S. Liu, 2001: Diagnostic evaluation on precipitation forecasts by the Central Weather Bureau's new generation regional forecast system (NFS). Proceeding, 2001 Con- 
ference on Weather Analysis and Forecasting, CWB, Taipei, Taiwan, 183-191. (in Chinese)

Shapiro, M. A. and A. J. Thorpe, 2002: The observing system research and predictability experiment (THORpex). Proceedings, International Conference on Mesoscale Convective Systems and Heavy Rainfall/Snowfall in East Asia, 29-31 October, Tokyo, Japan, 1-12.

Trier, S. B., C. A. Davis, D. A. Ahijevych, M. L. Weisman, and G. H. Bryan, 2006: Mechanisms supporting longlived episodes of propagating nocturnal convection within a 7-day WRF model simulation. J. Atmos. Sci., 63, 2437-2461, doi: 10.1175/JAS3768.1. [Link]

Wang, C. C., G. T. J. Chen, and R. E. Carbone, 2004: A climatology of warm-season cloud patterns over East Asia based on GMS infrared brightness temperature observations. Mon. Weather Rev., 132, 1606-1629, doi:
10.1175/1520-0493(2004)132<1606:ACOWCP>2.0. CO;2. [Link]

Wang, C. C., G. T. J. Chen, and R. E. Carbone, 2005: Variability of warm-season cloud episodes over East Asia based on GMS infrared brightness temperature observations. Mon. Weather Rev., 133, 1478-1500, doi: 10.1175/MWR2928.1. [Link]

Yu, R., T. Zhou, A. Xiong, Y. Zhu, and J. Li, 2007: Diurnal variations of summer precipitation over contiguous China. Geophys. Res. Lett., 34, L01704, doi: 10.1029/2006GL028129. [Link]

Zhao, Q., T. L. Black, and M. E. Baldwin, 1997: Implementation of the cloud prediction scheme in the Eta model at NCEP. Weather Forecast., 12, 697-713, doi: 10.11 75/1520-0434(1997)012<0697:IOTCPS>2.0.CO;2. [Link] 